\title{
DIAGNOSTIC BUBBLES
}

\author{
Pedro Bordalo \\ Nicola Gennaioli \\ Spencer Yongwook Kwon \\ Andrei Shleifer \\ Working Paper 25399 \\ http://www.nber.org/papers/w25399
}

\author{
NATIONAL BUREAU OF ECONOMIC RESEARCH \\ 1050 Massachusetts Avenue \\ Cambridge, MA 02138 \\ December 2018
}

Gennaioli thanks the European Research Council (GA 647782) for financial support. We are grateful to Nicholas Barberis, Lawrence Jin, Josh Schwartzstein, and Alp Simsek for helpful comments. The views expressed herein are those of the authors and do not necessarily reflect the views of the National Bureau of Economic Research.

NBER working papers are circulated for discussion and comment purposes. They have not been peer-reviewed or been subject to the review by the NBER Board of Directors that accompanies official NBER publications.

(C) 2018 by Pedro Bordalo, Nicola Gennaioli, Spencer Yongwook Kwon, and Andrei Shleifer. All rights reserved. Short sections of text, not to exceed two paragraphs, may be quoted without explicit permission provided that full credit, including $(\subset$ notice, is given to the source. 
Diagnostic Bubbles

Pedro Bordalo, Nicola Gennaioli, Spencer Yongwook Kwon, and Andrei Shleifer

NBER Working Paper No. 25399

December 2018

JEL No. G12,G4

\begin{abstract}
$\underline{\text { ABSTRACT }}$
We introduce diagnostic expectations into a standard setting of price formation in which investors learn about the fundamental value of an asset and trade it. We study the interaction of diagnostic expectations with two well-known mechanisms: learning from prices and speculation (buying for resale). With diagnostic (but not with rational) expectations, these mechanisms lead to price paths exhibiting three phases: initial underreaction, followed by overshooting (the bubble), and finally a crash. With learning from prices, the model generates price extrapolation as a byproduct of fast moving beliefs about fundamentals, which lasts only as the bubble builds up. When investors speculate, even mild diagnostic distortions generate substantial bubbles.
\end{abstract}

Pedro Bordalo

Saïd Business School

University of Oxford

Park End Street

Oxford, OX1 1HP

United Kingdom

pedro.bordalo@sbs.ox.ac.uk

Nicola Gennaioli

Department of Finance

Università Bocconi

Via Roentgen 1

20136 Milan, Italy

nicola.gennaioli@unibocconi.it
Spencer Yongwook Kwon

Department of Economics

Harvard University

1805 Cambridge Street

Cambridge, Mass 02138

United States

ykwon@hbs.edu

Andrei Shleifer

Department of Economics

Harvard University

Littauer Center M-9

Cambridge, MA 02138

and NBER

ashleifer@harvard.edu

A Code repository for simulations and graphs is available at https://github.com/spencerkwon/Bubbleproject_replication 


\section{Introduction}

The financial crisis of 2007-2008 has revived academic interest in price bubbles. Shiller (2015) created a famous graph of home prices in the United States over the course of a century, which shows prices being relatively stable during most of the $20^{\text {th }}$ century, then doubling over the ten year period after 1996 , only to collapse in the crisis and begin recovering after 2011. There is also growing evidence of speculation such as buying for resale in the housing market (DeFusco, Nathanson, and Zwick 2018, Mian and Sufi 2018) and of increasing leverage of both homeowners and financial institutions tied to rapid home price appreciation. The collapse of the housing bubble is at the heart of every major narrative of the financial crisis and the Great Recession because it entailed massive losses for homeowners, holders of mortgage backed securities, and financial institutions (Mian and Sufi 2014). Nor is the U.S. experience unique. Leverage expansions and subsequent crises are often tied to bubbles in housing and other markets (Jorda, Schularick and Taylor 2015).

Despite the revival of academic interest, asset price bubbles remain controversial in finance. Although economic historians tend to see bubbles as self-evident (Mackay 1841, Bagehot 1873, Galbraith 1954, Kindleberger 1978, Shiller 2000), Fama (2014) raised the critical question of whether they even exist in the sense of predictability of future negative returns after prices have increased substantially. Interestingly, since Smith, Suchanek and Williams (1988), predictably negative returns are commonly found in laboratory experiments even when markets have finite horizons. Greenwood, Shleifer, and You (2018) address Fama’s challenge in industry stock return data around the world, and find that although past returns alone are very noisy indicators of bubbles, other measures of over-pricing do forecast poor returns going forward ${ }^{2}$.

Early theoretical research has focused on rational price bubbles that do not violate (some definitions of) market efficiency (e.g., Blanchard and Watson 1982, Tirole 1985, Martin and Ventura 2012), but these models are not consistent with the available evidence on prices (Giglio, Maggiori, and Stroebel 2016). They are also rejected by the striking evidence of excessively optimistic investor expectations in bubble episodes (Case et al. 2012, Greenwood, Shleifer, and You 2018), which also shows up in experimental data (e.g., Haruvy et al. 2007). Because of such evidence, research has moved to behavioral models of bubbles, which emphasize

\footnotetext{
${ }^{2}$ A closely related literature examines the overpricing of small growth stocks with extremely optimistic analyst forecasts of future growth, and predictably poor returns (Lakonishok et al. 1994, La Porta 1996, Bordalo et al. 2018).
} 
factors such as overconfidence and short sales constraints (Scheinkman and Xiong 2003), neglect of entry (Glaeser et al 2008, Glaeser and Nathanson 2017, Greenwood and Hanson 2014), and extrapolation (e.g., Cutler et al. 1990, DeLong et al 1990b, Barsky and DeLong 1993, Hong and Stein 1999, Barberis and Shleifer 2003, Hirshleifer et al. 2015, Glaeser and Nathanson 2017, Barberis et al. 2015, 2018).

Despite substantial advances, many important conceptual questions about price bubbles remain open. What is the role of innovation, or substantial positive news, in getting bubbles started? Are bubbles driven by the extrapolation of fundamentals, or of returns themselves? Can price increases become self-reinforcing and disconnected from fundamental news? And what are the respective roles of optimistic beliefs about fundamental value versus speculation for quick resale in sustaining price growth?

In this paper, we revisit some of these questions starting from a psychologically founded model of belief formation. We embrace Kindleberger's (1978) view of bubbles as consisting of three stages. The first is displacement, meaning a period of good fundamental news, often tied to an economic innovation (see, e.g, Pastor and Veronesi 2006), that lead to rapid asset price increases. The second and crucial period is the acceleration of price growth, as price increases themselves encourage buying and further price increases, and prices reach levels substantially above fundamental values. The third period is the price collapse, as traders are disappointed and sell the assets. We do not examine leverage and other factors that link the collapses of bubbles to financial fragility and economic recessions (see, e.g., Gennaioli, Shleifer, and Vishny 2012, Reinhart and Rogoff 2009, Gennaioli and Shleifer 2018). Our goal is instead to link expectations to the mechanics of a bubble, including price acceleration and subsequent collapse.

We examine the model of Diagnostic Expectations (see Bordalo, Gennaioli, and Shleifer, hereafter BGS 2018, Bordalo, Gennaioli, La Porta and Shleifer, hereafter BGLS 2018, and Bordalo, Gennaioli, Ma, and Shleifer, hereafter BGMS 2018), which relates beliefs to Kahneman and Tversky’s (1972) representativeness heuristic. Representativeness refers to the notion that, in forming probabilistic assessments, decision makers put too much weight on outcomes that are likely not in absolute terms, but rather relative to some reference or baseline level. For example, many people significantly over-estimate the probability that a person's hair is red when told that the person is Irish. The share of red-haired Irish, at $10 \%$, is a small minority, but red hair is much more common among the Irish than among other Europeans, let alone in the world as a whole. The 
over-estimation of the prevalence of representative types distorts beliefs and accounts for many systematic errors in probabilistic judgments documented experimentally (Gennaioli and Shleifer 2010). It also delivers a theory of stereotypes consistent with both field and experimental evidence, including gender stereotypes in assessments of ability (Bordalo et al. 2018), racial stereotypes in decisions about bail (Arnold, Dobbie and Yang 2018), and popular beliefs about immigrants (Alesina, Miano, and Stantcheva 2018).

In a market context, diagnostic expectations describe how traders update their beliefs in response to new information. Under Rational Expectations, the answer to this question is given by the Bayes Rule. Under Diagnostic Expectations, traders update their beliefs too far in the direction of the states of the world whose objective likelihood has increased the most in light of recent news. After good news, right-tail outcomes become representative and are overweighed in expectations, while left-tail outcomes become nonrepresentative and are neglected. This form of over-reaction can lead to overvaluation of financial assets after good news (BGLS 2018). Here we ask whether it leads to other aspects of the Kindleberger narrative, such as gradual buildup of prices, extrapolation, acceleration of price growth, and eventual price collapse.

To address these questions, we incorporate diagnostic expectations into a standard finite horizon model of a market for one asset, in which there is a continuum of investors receiving noisy private information every period about the termination value of that asset. To capture Kindleberger's displacement, we assume the asset is valuable (above the prior) so that traders on average receive good news about fundamentals every period. Because traders receive different noisy signals, they hold heterogeneous beliefs. Heterogeneity also generates trading volume, which is an important feature of bubbles (Scheinkman and Xiong 2003, Hong and Stein 2007).

To fix ideas, in Section 2 we describe learning under diagnostic expectations. In Section 3, we present a model of long horizon investors who learn from prices, and examine how prices respond to a series of good news. In Section 4, we modify the model to consider short horizon traders whose objective reflects not the final value of the asset, but next period price. We can thus examine speculation - buying for resale - which is a central feature of many narratives of the bubbles, including Kindleberger's. Under Rational Expectations, in both of these models the average price path increases from the prior to the fundamental value. Whether or not there is learning from prices, there is no overshooting, and hence there are no price bubbles in equilibrium. 
A model with learning from prices and diagnostic expectations, in contrast, generates some interesting features of a bubble. As good news come in and prices rise, diagnostic traders act more aggressively on their private signals, which makes prices more informative than under the rational benchmark. As a consequence, traders react even more aggressively to price signals, which quickly swamp the less informative private ones. Prices not only exceed fundamental values in equilibrium, but also accelerate as the bubble develops. In fact, it looks like investors are extrapolating price trends, even though they are not. Instead, recent price increases lead traders to upgrade (too much) their expectations of fundamental value, and thus of the future price. Despite some plausible intuitions, the model in Section 3 does not deliver wild prices because equilibrium prices are still tethered to eventual liquidation values.

In Section 4, we introduce speculation by having traders optimize relative to their beliefs of the next period price rather than the eventual liquidation value of the asset. Unlike previous models of speculation, such as Harrison and Kreps (1978) and Scheinkman and Xiong (2003), we do not need to assume short sale constraints. This modification has dramatic consequences. Even without learning from prices, traders can drive prices extremely high, because speculation compounds overreaction: traders are not only too optimistic about fundamentals, they also exaggerate the possibility of reselling the asset to over-reacting traders in the future. Following a beauty context logic, a trader who believes that the asset is the next Google thinks that future diagnostic traders will receive extremely positive signals and will thus be even more optimistic about the asset. The expectation of reselling the asset to very bullish traders further inflates the price today. Eventually, as the terminal date approaches, the opportunities for resale become scarcer and the bubble collapses.

Along with diagnostic expectations, speculation emerges as a central feature of price bubbles, at least in terms of the three Kindleberger phases. When combined with learning from prices, speculation disconnects expectations of fundamentals from expectations of price increases. Even a small deviation from rationality in the form of diagnostic overreaction compounds into strong price extrapolation and large price dislocations. 


\section{Learning from Good Shocks and the Dynamics of Diagnostic Expectations}

Our basic setup is as follows. Traders learn about the value of a new asset over a finite number of periods $t=0, \ldots, T$. The asset yields a payoff $V$ drawn from a normal distribution with mean 0 and variance $\sigma_{V}^{2}$ at $t=0$ but is only revealed at the terminal date $T$. In line with Kindelberger's (1978) description of a positive displacement as the trigger of bubble episodes, we focus on the case of a valuable innovation, $V>0$. In each period $t$, each trader $i$ (in measure one) receives a private signal $s_{i t}=V+\epsilon_{i t}$ of the asset's value. Noise $\epsilon_{i t}$ is i.i.d. across traders and over time, and normally distributed with mean zero and variance $\sigma_{\epsilon}^{2}$. Because the new asset is valuable, $V>0$, traders are repeatedly exposed to good news, in that signals are on average positive relative to their priors, capturing the initial displacement. Moreover, the assumption of dispersed information generates variation in expectations and helps account for trading.

In this Section, we do not consider trading, and describe instead how Diagnostic Expectations about fundamentals evolve solely based on the arrival of noisy private signals over time. This is useful for two reasons. First, in this setting with learning and dispersed information, Diagnostic Expectations behave differently than in prior finance applications (BGS 2018, BGLS 2018). Second, by separately characterizing the dynamics of expectations about fundamentals, we can better understand their interaction with market forces such as trading, learning from prices, and speculation, which we introduce in Sections 3 and 4.

A rational trader observing a history of signals $\left(s_{i 1}, \ldots, s_{i t}\right)$ forms an expectation about $V$ given by:

$$
\mathbb{E}_{i t}(V)=\pi_{t} \frac{\sum_{r=1}^{t} s_{i r}}{t}
$$

where $\pi_{t} \equiv \frac{t / \sigma_{\epsilon}^{2}}{t / \sigma_{\epsilon}^{2}+1 / \sigma_{V}^{2}}$ is the signal to noise ratio. Prices will be driven by the consensus expectation, given by

$$
\int \mathbb{E}_{i t}(V) d i=\pi_{t} V
$$

The consensus expectation of rational traders exhibits two important properties. First, it is always below the rational benchmark because $\pi_{t} \leq 1$. Rational traders discount their noisy signals, which implies that average information, always equal to $V$, is also discounted. Second, the consensus expectation gradually 
improves over time, because the signal to noise ratio $\pi_{t}$ rises, in a concave way, toward one. As the trader sees more and more signals, his uncertainty falls, inducing him to weigh his evidence more heavily.

As in rational inattention or noisy information models (Woodford 2003), optimal information processing by individuals who observe noisy signals creates sluggishness in consensus expectations. This sluggishness is central in thinking about price formation in rational expectations models. Indeed, as we show in Sections 3 and 4, rational updating implies that the price of the asset monotonically converges to fundamental value from below, just as consensus expectations do.

Consider now updating under Diagnostic Expectations (DE) in a model of beliefs formation. ${ }^{3}$ In an intertemporal setting like the current one, this model captures the idea that, when forming beliefs about the future, investors overweight the probability of events that have become more likely in light of recent news. For instance, after observing a period of positive earnings growth, DE overweight the probability that the firm may be the next Google. Even though this event is highly unlikely in absolute terms, it has become more likely in light of the strong earnings growth. As a consequence, the perceived probability of such an event is inflated.

As shown in BGS (2018), if the random variable $X_{t+1}$ is conditionally normal, the diagnostic distribution of beliefs is also normal. ${ }^{4}$ Furthermore, if $\mathbb{E}_{s}\left(X_{t+1}\right)$ is the rational expectation at time $s$, then the diagnostic expectation at time $t$ is:

$$
\mathbb{E}_{t}^{\theta}\left(X_{t+1}\right)=\mathbb{E}_{t-k}\left(X_{t+1}\right)+(1+\theta)\left[\mathbb{E}_{t}\left(X_{t+1}\right)-\mathbb{E}_{t-k}\left(X_{t+1}\right)\right],
$$

$\mathrm{DE}$ are forward looking: they update in the correct direction and nest rational expectations as a special case for $\theta=0$. Crucially, however, DE overreact to information by exaggerating the difference between current conditions $\mathbb{E}_{t}\left(X_{t+1}\right)$ and normal conditions $\mathbb{E}_{t-k}\left(X_{t+1}\right)$ by a factor of $(1+\theta)$. As good news arrives, the right tail of $X_{t+1}$ becomes fatter; while still unlikely, this right tail is very representative because its prior

\footnotetext{
${ }^{3}$ According to Kahneman and Tversky (1972), the reliance on representativeness as a proxy for likelihood is a central feature of probabilistic judgments. An outcome "is representative of a class if it's very diagnostic", that is, if its "relative frequency is much higher in that class than in the relevant reference class" (Tversky and Kahneman 1983).

${ }^{4}$ Following BGS (2018), in a Markov process with density $f\left(X_{t+1} \mid X_{t}\right)$, after a particular current state $\widehat{X}_{t}$ is realized and in light of the past expectation for the current state $\mathbb{E}_{t-k}\left(X_{t}\right)$, the distorted distribution is equal to:

$$
f^{\theta}\left(X_{t+1} \mid X_{t}\right)=f\left(X_{t+1} \mid X_{t}\right)\left[\frac{f\left(X_{t+1} \mid \hat{X}_{t}\right)}{f\left(X_{t+1} \mid \mathbb{E}_{t-k}\left(X_{t}\right)\right)}\right]^{\theta} Z_{t},
$$

where both the target $f\left(X_{t+1} \mid \hat{X}_{t}\right)$ and reference distribution $f\left(X_{t+1} \mid \mathbb{E}_{t-k}\left(X_{t}\right)\right)$ have equal variance. Roughly speaking, beliefs overweigh states that have become more likely in light of the surprise $\widehat{X}_{t}-\mathbb{E}_{t-k}\left(X_{t}\right)$ relative to $k$ periods ago.
} 
probability was so low. As a result, investors overweight the right tail and neglect the risk in the left tail. For normal distributions, this reweighting results in an excessive rightward shift of beliefs.

In Equation (2), lag $k$ defines which recent news investors over-react to. For $k=1$, investors only overreact to news received in the current period, so after one period past good news are immediately perceived as normal. For $k>1$, the investor over-reacts to the last $k$ pieces of news. This captures a realistic sluggishness in the perception of normal conditions: new evidence becomes normal only after enough time has passed. Put differently, the investor observing a sequence of good news takes a while to adapt to them.

BGLS (2018) show that in a setting where traders learn from homogeneous information, diagnostic expectations obtained from Equation (2) account well for the link between listed firms' performance and equity analysts' expectations of their future earnings growth, as well as, crucially, for the link between expectations and the predictability of their stock returns. They estimate the model and find that, with quarterly data, $\theta \approx 1$ and $k \approx 3$ years. A similar value of $\theta$ has been estimated using expectations of credit spreads by BGS, and using macroeconomic forecasts by BGMS. Later we use $k \approx 3$ years in our simulation exercises.

The current model, relative to earlier finance applications of DE, we introduce two new ingredients. First, each trader observes a different noisy signal of the truth $V$. Second, the state $V$ does not change over time, reflecting learning about, say, the potential of a new technological innovation. We next show that under these two assumptions DE generate rich dynamics that look promising for studying bubble episodes.

Given the heterogeneity of information at time $t$ each trader $i$ has a different diagnostic expectation $\mathbb{E}_{i t}^{\theta}(V)$. As before, we focus on the consensus diagnostic expectation. This is given by:

$$
\int \mathbb{E}_{i t}^{\theta}(V) d i=\left\{\begin{array}{cc}
(1+\theta) \pi_{t} V & \text { for } t \leq k \\
{\left[\pi_{t}+\theta\left(\pi_{t}-\pi_{t-k}\right)\right] V} & \text { for } t>k
\end{array} .\right.
$$

Equation (3) implies that, under DE, consensus expectations exhibit boom bust dynamics.

Proposition 1 If $\theta \in\left(\frac{1}{k} \frac{\sigma_{\epsilon}^{2}}{\sigma_{v}^{2}}, \frac{\sigma_{\epsilon}^{2}}{\sigma_{v}^{2}}\right)$, the consensus diagnostic expectation $\mathbb{E}_{t}^{\theta}(V)$ exhibits three phases:

1) Delayed over-reaction: $\mathbb{E}_{t}^{\theta}(V)$ starts below $V$, then increases to its peak $\mathbb{E}_{t}^{\theta}(V)=(1+\theta) \pi_{k} V$ at $t=k$. 
2) Bust: $\mathbb{E}_{t}^{\theta}(V)$ drops from $t=k+1$ to $t^{*}$, reaching its through $\mathbb{E}_{t^{*}}^{\theta}(V)<V$.

3) Recovery: $\mathbb{E}_{t}^{\theta}(V)$ gradually recovers for $t>t^{*}$, asymptotically converging to the fundamental $V$.

In a noisy environment, adding a modicum of overreaction $\theta$ to recent signals upsets the monotone convergence of rational expectation, yielding rich beliefs dynamics. Early on, consensus opinion under-reacts to the fundamental displacement, $\mathbb{E}_{t}^{\theta}(V)<V$, so that in this range the behavior of DE is qualitatively similar to rational learning. Because diagnostic traders are forward looking, they discount the noise in their signals. Initially, when uncertainty about $V$ is large, this discounting is sufficiently strong that it counteracts the tendency of each individual to overreact (as long as overreaction is moderate, $\theta<\frac{\sigma_{\epsilon}^{2}}{\sigma_{v}^{2}}$ ). As a result, in early stages, consensus beliefs about $V$ improve sluggishly, gradually incorporating the good signals of traders.

The possibility that in a noisy environment individual over-reaction is consistent with sluggishness of consensus expectations is not just theoretical. BGMS (2018) document this phenomenon in professional forecasts of macroeconomic variables. When expectations are heterogeneous, as is empirically the case, information contained in the average is lost, creating apparent under-reaction.

As traders receive good signals, however, they grow more confident about the value of the asset. As a result, they incorporate their signals more aggressively into their beliefs. At some point, their signal to noise ratio $\pi_{t}$ becomes sufficiently high that, for a given amount of diagnosticity $\theta$ we have:

$$
(1+\theta) \pi_{t}>1
$$

Consensus under-reaction now turns to overreaction. Displacement causes traders to be so confident that beliefs overshoot the fundamental, $\mathbb{E}_{t}^{\theta}(V)>V$. Overshooting of fundamentals stands in stark contrast not only to the rational benchmark but also to any model of mis-specified learning in which beliefs are a convex combination of priors and new information, including overconfidence (Daniel, Hirshleifer and Subrahmanyam 1998). ${ }^{5}$ This distinctive feature reflects the fact that diagnostic expectations generate disproportional and asymmetric weight on tail events: if traders focus on the right tail and neglect the left tail, then in some sense

\footnotetext{
${ }^{5}$ Overconfidence is a different form of over-reaction to private news in which traders exaggerate the precision of their private signals. It implies an inflated signal to noise ratio relative to rational expectations, but still be below 1 . This generates a price path lying above the rational benchmark, but never overshooting or exhibiting a boom-bust path.
} 
"the sky is the limit”: sufficiently many good signals about $V$ bring to mind stratospheric values, each fast growing firm is believed to be a new Google, and trees are expected to grow to the sky. This result is in line with the standard narrative of bubbles, in which the initial displacement leads investors to believe in a "paradigm shift” capturing the most optimistic scenarios that could result from the innovation. ${ }^{6}$

Beliefs revert after $k$ periods, when over-reaction to early signals wanes. After a while, traders view these signals as normal and focus on the information contained in the new, most recent, signals. Because these signals have a smaller and smaller incremental value ( $V$ is finite), they cannot sustain the exorbitant optimism of the boom. As a result, optimism in beliefs starts deflating. The bust here is due not to bad news, but to the declining pace at which good news arrive, which causes optimism to run out of steam. After the bust, when expectations reach their trough and get close to rational beliefs, over-reaction to good news is negligible (because good news are minor), and the consensus converges to $V$ from below.

In sum, by introducing some over-reaction to recent news in an otherwise standard noisy information model, diagnostic expectations can account for initial rigidity of consensus expectations, delayed over-reaction of beliefs to fundamental news, and subsequent reversals as dramatic good news stop coming. This mechanism seems promising for thinking about bubbles. Insofar as prices reflect consensus beliefs, diagnostic expectations may account for sluggish boom bust price dynamics that cannot be obtained under rationality. Still, other features of this simple formulation are hard to reconcile with bubbles. First, expectations of fundamentals in Equation (3) improve in a concave way, which is hard to square with the observed convex price paths during bubbles (Greenwood, Shleifer, and Yang 2018). Second, for realistic parameter values over-optimism about fundamentals is small relative to the price inflation observed in bubble episodes. Using $\theta=1$ as estimated using expectations of earnings growth (BGLS 2018), and of macroeconomic time series (BGMS 2018), suggests that valuation at the peak is bounded above by $2 \mathrm{~V}$. In some historical episodes, such as the internet bubble, prices reached multiple times the plausible measures of fundamentals.

To address these challenges, we next combine diagnostic expectations about fundamentals with two standard mechanisms that do not yield the three phases of bubbles in rational models: learning from prices and

\footnotetext{
${ }^{6}$ In Pastor and Veronesi (2009), a successful innovation is not initially overpriced, but instead becomes central enough to the economy that the risk associated with it becomes systematic, which in turn depresses prices.
} 
speculation. We show that combining these standard market mechanisms with a modicum of diagnosticity about fundamentals is able to reproduce key features of bubble episodes, including convex price paths and strongly inflated prices. Prices growth becomes disconnected from growth in fundamentals.

\section{Diagnostic Learning from Prices}

We now analyze trading when traders learn not only from private signals, but also from market prices. This is an important feature of real world markets, enabling traders to extract from price changes the information that other traders have about fundamentals. Starting with Grossman (1976) and Grossman and Stiglitz (1980), learning from prices plays an important role in formal analyses of rational expectations equilibria in financial markets. Here we study its consequences under diagnostic expectations.

The market setting is as follows. At each $t=0,1 \ldots$, traders exchange the asset and determine its price. They learn about the fundamental $V$ from current and past private signals as well as from all prices observed up to the last period. ${ }^{7}$ Traders are risk averse with CARA utility $u(c)=-e^{-\gamma c}$, and they have long horizons, in that they value the asset by their assessment of its fundamental value $V$. There is no time discounting.

To determine the demand for the asset at time $t$, suppose that trader $i$ believes that $V$ is normally distributed with mean $\mathbb{E}_{i t}^{\theta}(V)$ and variance $\sigma_{t}^{2}(V)$, where $\theta$ denotes diagnostic expectations. ${ }^{8}$ With exponential utility and normal beliefs, his preferences are described in terms of mean and variance. Trader $i$ 's demand $D_{i t}$ of the asset maximizes the mean-variance objective function:

$$
D_{i t}=\max _{\widehat{D}_{i t}}\left[\mathbb{E}_{i t}^{\theta}(V)-p_{t}\right] \widehat{D}_{i t}-\frac{\gamma}{2} \sigma_{t}^{2}(V) \widehat{D}_{i t}^{2}
$$

where $\gamma$ captures risk aversion. Trader $i$ 's demand $D_{i t}$ is then given by:

\footnotetext{
${ }^{7}$ If investors learn also from the current price, the equilibrium may fail to exist for $t>k$. We thus focus on learning from past prices, which guarantees existence, but the models behave very similarly when equilibrium exists. To study speculation, because we set $k$ to be high, existence is guaranteed and so we allow investors to learn from the current price. ${ }^{8}$ As we discussed in Section 2, diagnostic beliefs are normal. This is shown in the appendix, where we also show that the variance $\sigma_{t}^{2}(V)$ is not distorted under our specification.
} 


$$
D_{i t}=\frac{\mathbb{E}_{i t}^{\theta}(V)-p_{t}}{\gamma \sigma_{t}^{2}(V)}
$$

Intuitively, demand increases in the difference between the trader's valuation and the market price.

To make learning from prices non-degenerate, we follow the literature and assume that that the supply $S_{t}$ of the asset is random, i.i.d. normal with mean zero and variance $\sigma_{S}^{2}$ (without supply shocks $V$ is learned in one period). The classical justification here is the presence of noise or liquidity traders who demand/supply the assets for non-fundamental reasons (Black 1986, Grossman and Miler 1988, DeLong et al. 1990a). The implication is that price is no longer fully revealing: high price today may be due either to a low unobserved supply $S_{t}$ shock or to a high average private signal $V$.

By aggregating individual demands in Equation (4) and by equating to supply we find:

$$
p_{t}=\int \mathbb{E}_{i t}^{\theta}(V) d i-\gamma \sigma_{t}^{2}(V) S_{t}
$$

To solve for the equilibrium in Equation (5), we must compute the diagnostic consensus expectation at time $t$, recognizing that it depends both private signals and past prices. Because DE are forward looking, it is possible to amend the consensus beliefs in Equation (3) to reflect diagnostic learning from prices. As in rational expectations models (Grossman and Stiglitz 1980), we first conjecture that, at each time $t$, price is a linear function of the state variables of the economy, which include the fundamental $V$. Second, we assume that traders use this linear rule to make inferences about $V$ in light of the current and past prices. Third, we determine at each time $t$ the coefficients of the pricing function that equilibrate demand and supply, so that the resulting rule yields the equilibrium price.

Denote by $\mathbb{E}\left(V \mid P_{t}\right)$ the rational expectation of $V$ based solely on the history of prices up to $t$, formally $P_{t} \equiv\left(p_{1}, \ldots, p_{t-1}\right)$. Then, our conjectured pricing rule takes the form: ${ }^{9}$

$$
p_{t}=a_{1 t}+a_{2 t} \mathbb{E}\left(V \mid P_{t}\right)+a_{3 t} \mathbb{E}\left(V \mid P_{t-k}\right)+b_{t}\left(V-\frac{c_{t}}{b_{t}} S_{t}\right)
$$

\footnotetext{
${ }^{9}$ The price could equivalently be assumed to be linear in the diagnostic expectation $\mathbb{E}^{\theta}\left(V \mid P_{t}, s_{i 1}=\cdots=s_{i t}=0\right)$ held by traders held solely on the basis of prices (i.e. assuming that private signals are neutral).
} 
Equation (6) is reminiscent of rational expectations analyses. The current price reflects consensus expectations derived from all prices up to date $t$, as well as the average private signal. Because diagnostic expectations combine current and lagged rational forecasts, the lagged forecast is also added as a state variable.

To solve for the diagnostic expectations equilibrium (DEE), we must find the coefficients $\left(a_{1 t}, a_{2 t}, a_{3 t}, b_{t}, c_{t}\right)_{t \geq 1}$ that equate supply with demand when traders make diagnostic inferences from prices. We now sketch the logic of the result, and leave a fuller account to the proof in Appendix A.

First, consider how traders learn in light of the pricing rule. Because diagnostic traders over-react to news, they over-react also to the shared news coming from prices. To compute the diagnostic expectations with learning from prices, we proceed in two steps. We compute the rational expectations when prices are generated by Equation (6), and then apply the diagnostic transformation of Equation (2). ${ }^{10}$

The rational news conveyed by price at time $r$ is captured by the term $p_{r}-a_{1 r}-a_{2 r} \mathbb{E}\left(V \mid P_{r}\right)-$ $a_{3 r} \mathbb{E}\left(V \mid P_{r-k}\right)$ as well as by the coefficients $b_{r}$ and $c_{r}$, which are known by all (in equilibrium). That is, observing $p_{r}$ effectively endows all traders with the following unbiased public signal of $V$ :

$$
s_{r}^{p}=V-\left(\frac{c_{r}}{b_{r}}\right) S_{r}
$$

The variance of the signal, which is the inverse of its precision, is equal to $\left(c_{r} / b_{r}\right)^{2} \sigma_{S}^{2}$. Intuitively, the price is more informative when it is more sensitive to the persistent fundamental than to the transient supply shock, namely when $c_{r} / b_{r}$ is lower. This price sensitivity is an endogenous part of the equilibrium, and later we characterize it in terms of primitives.

Since private and public signals $s_{i t}$ and $s_{t}^{p}$ are normally distributed, conditional on a history of signals $\left(s_{i 1}, \ldots s_{i t}, s_{1}^{p}, \ldots s_{t}^{p}\right)$, a rational trader's beliefs about $V$ are normal with mean:

$$
\mathbb{E}_{i, t}(V)=\bar{s}_{i, t} z_{t}+\mathbb{E}\left(V \mid P_{t}\right)\left(1-z_{t}\right)
$$

\footnotetext{
${ }^{10}$ In the appendix we show that the diagnostic expectations so obtained are equivalent to those obtained by applying the distorted distribution of footnote 4 to the true distribution $f\left(V \mid s_{i 1},,, s_{i t}, P_{t}\right)$ conditional on private signals and prices.
} 
The rational inference combines the private signals with the price signals embodied in $\mathbb{E}\left(V \mid P_{t}\right)$. The weight $z_{t}$ attached to the private signals is given by: ${ }^{11}$

$$
z_{t}=\frac{t}{\sigma_{\epsilon}^{2}}\left[\frac{t}{\sigma_{\epsilon}^{2}}+\frac{1}{\sigma_{p, t}^{2}(V)}\right]^{-1}
$$

where $\sigma_{p, t}^{2}(V)$ is the variance of the fundamental conditional only on prices. The weight $z_{t}$ attached to private signals is higher when the informativeness of prices is low (when $\sigma_{p, t}^{2}(V)$ is high).

To compute diagnostic consensus beliefs, we need to: i) compute diagnostic beliefs by transforming rational beliefs in Equation (10) according to Equation (2), and ii) aggregate the resulting beliefs into the consensus. The implied consensus dynamics works as follows:

$$
\int \mathbb{E}_{i t}^{\theta}(V) d i=\left\{\begin{array}{cc}
(1+\theta)\left[\left(1-z_{t}\right) \mathbb{E}\left(V \mid P_{t}\right)+V z_{t}\right] & \text { for } t \leq k \\
(1+\theta)\left(1-z_{t}\right) \mathbb{E}\left(V \mid P_{t}\right)-\theta\left(1-z_{t-k}\right) \mathbb{E}\left(V \mid P_{t-k}\right)+\left[(1+\theta) z_{t}-\theta z_{t-k}\right] V & \text { for } \quad t>k
\end{array}\right.
$$

There are two important messages. First, diagnostic expectations exaggerate the information revealed by prices, not only private information. This exaggeration comes from the amplification $(1+\theta)$ of the impact of the current price-based estimate $\mathbb{E}\left(V \mid P_{t}\right)$, and from the reversal of past price inferences $\mathbb{E}\left(V \mid P_{t-k}\right)$. This is another difference from overconfidence, in which public information - including that coming from prices - is underweighted. Because a price increase says that positive information about fundamentals is dispersed in the economy, it renders the right tail representative, causing overreaction in beliefs. Second, if prices become very informative over time, the weight $z_{t}$ attached to private signals falls and the weight attached to prices increases. The effects of information dispersion may thus subside, and the dynamics of beliefs may be very different from what we saw in Section 2.

\subsection{The Boom Phase} 11 The variance of $V$ is equal to $\sigma_{t}^{2}(V)=\left[\frac{t}{\sigma_{\epsilon}^{2}}+\frac{1}{\sigma_{p, t}^{2}(V)}\right]^{-1} \cdot \sigma_{p, t}^{2}(V)$ decreases in the precision of the public signals observed
up to $t$. See the appendix for details. 
To assess whether learning from prices significantly affects beliefs and prices, we need to solve for the coefficient of price informativeness $c_{r} / b_{r}$. It may in fact be that diagnosticity reduces price informativeness, moderating overreaction to price signals. We need to find a fixed point at which consensus beliefs are consistent with market equilibrium in Equation (5). Here the key result comes from considering the equilibrium for the boom phase of the bubble, $t \leq k$.

Proposition 2 With learning from prices and $t \leq k$, the average consensus belief about $V$ is higher than the average consensus belief formed when investors learn from private information alone. The precision of the equilibrium price signal increases over time as:

$$
\frac{b_{t}}{c_{t}}=\left(\frac{1+\theta}{\gamma \sigma_{\epsilon}^{2}}\right) t
$$

and the average equilibrium price path (for $S_{1}=S_{2}=\cdots=S_{t}=0$ ) is given by:

$$
p_{t}=(1+\theta)\left[\frac{\frac{t}{\sigma_{\epsilon}^{2}}+\left(\frac{1+\theta}{\sigma_{S} \sigma_{\epsilon}^{2}}\right)^{2} \frac{t(t-1)(2 t-1)}{6}}{\frac{t}{\sigma_{\epsilon}^{2}}+\frac{1}{\sigma_{\mathrm{V}}^{2}}+\left(\frac{1+\theta}{\sigma_{S} \sigma_{\epsilon}^{2}}\right)^{2} \frac{t(t-1)(2 t-1)}{6}}\right] V .
$$

As in the consensus expectations described in Section 2, the equilibrium price grows in the boom phase $t \leq k$, before investors adapt to the displacement. The price in Equation (12) increases over time. If $\theta$ in in the range of Proposition 1, the price starts below the fundamental $V$. This initial under-reaction is due to the same reason that consensus beliefs underreact: traders discount the noise in their signals, so the good news they on average receive is not incorporated into prices.

As time goes by, the price increases due to two forces. First, as traders accumulate private signals, they gain confidence about the innovation and revise their beliefs upward. This effect is captured by the term $t / \sigma_{\epsilon}^{2}$ in Equation (12). Second, the observation of prices provides on average additional good news about displacement and that makes all traders more confident at the same time. As a result, the consensus estimate of $V$ increases relative to the case in which only private signals are observed, and the price booms. The effect of learning from prices is captured by the second term in the numerator of Equation (12). At some point, traders become so confident that the price over-reacts, overshooting the fundamental $V$. 
How does diagnosticity interact with learning from prices? And how does learning from prices contribute to the price path? Equation (11) answers the first question. Stronger diagnosticity $\theta$ increases the informativeness of prices. When $\theta$ is higher, investors are aggressive both in revising their beliefs and in trading on the basis of their private signals. Because these signals are informative about $V$, price informativeness increases. In turn, greater price informativeness implies that diagnostic traders over-react faster to the price signals, which implies that the bubble arises earlier. Unlike non-fundamental based behavioral biases, such as mechanical extrapolation, which disconnect prices from fundamentals, diagnostic expectations exaggerate this link, creating faster and accelerating overreaction to the initial displacement.

To see how learning from prices influences the price path, consider again Equation (11). It says that, for a given $\theta$, the price signal becomes more informative over time. As the i.i.d. supply shocks average out over time, a path of consistent price increases is highly informative of good fundamentals. Consequently, learning from prices progressively gains ground, and swamps private signals as prices rise up to the peak of the bubble. As shown in Equation (12) the precision of price signals grows with the cubic power of $t$, which eventually swamps the linear precision of private signals, $t / \sigma_{\epsilon}^{2}$. This has the following implication.

Proposition 3 With learning from prices, there exists $a \sigma_{V}^{2 *}>0$ such that for $\sigma_{V}^{2}<\sigma_{V}^{2 *}$ there exists a $t^{*}>0$ such the average price path is convex for $t<t^{*}$ and concave for $t \in\left(t^{*}, k\right)$. When the supply shocks are so volatile $\left(\sigma_{S} \rightarrow \infty\right)$ that prices convey no information, the price path is concave: $\sigma_{V}^{2 *} \rightarrow 0$.

When fundamental displacement is sufficiently large ( $\sigma_{V}^{2}$ is low enough), learning from prices generates a price path that is initially convex and then slows down as the bubble reaches its peak. This occurs because all traders, regardless of their private signals, aggressively infer fundamentals from the common price signal, so the price informativeness increases at first. After sufficient information has been incorporated into expectations and prices, the value of additional signals diminishes, which causes a price growth slowdown.

Under rational expectations, learning from prices would also coordinate traders’ beliefs and generate convexity in prices, but not lead to overvaluation. In contrast, under diagnostic expectations convex price growth eventually overshoots the fundamentals, creating a bubble. In this respect, with learning from prices, diagnostic expectations generate a boom phase where the price initially under-reacts, but as displacement 
continues and as the price increases, traders make strong inferences and push the price even higher, generating a convex price increase and eventually an overvaluation. Allowing for learning from prices thus remedies the first shortcoming of the model of Section 2: it creates the convex price paths typical of real world bubbles.

\subsection{Model Simulation: Boom, Bust and Price Extrapolation}

To explore the entire path of the bubble, we resort to simulations, because the model cannot be analytically solved for $t>k$. This analysis shows that diagnostic expectations can produce the boom and bust phases of bubbles and the dynamics of investor disagreement (and hence trading). Most importantly, diagnostic expectations can endogenously produce extrapolative expectations of prices, but in a way that distinguishes them from adaptive expectations or from alternative formulations (Hong and Stein 1999, Glaeser and Nathanson 2017). The predictions may also suggest how to detect bubbles in the data.

We now describe our choice of parameters. We normalize $V$ to 1 . To capture that displacement is a fairly rare event, we assume $\sigma_{V}=0.5$, so $V$ is two standard deviations away from the mean. The dispersion of trader's private signals is set at $\sigma_{\epsilon}=12.5$, which is in the ballpark of what we estimated from the quarterly dispersion of professional forecasts (BGMS 2018). ${ }^{12}$ We set $\theta=0.8$, in line with the quarterly estimates from macroeconomic and financial survey data. For the model without speculation, we take a time period to be a quarter, set the sluggishness of diagnostic beliefs at $k=12$ (in line with the estimates from BGLS 2018) and run the model for $T=24$ periods, i.e. 6 years. We set the volatility of supply shocks at $\sigma_{S}=0.3$.

Figure 1 reports the actual price for the average path (no supply shocks) both under diagnostic expectations $(\theta=0.8)$ and under rational expectations $(\theta=0)$. Under diagnostic expectations, the equilibrium price exhibits the typical boom bust pattern, where the boom is driven by overreaction to private signals and prices, while the bust is due to the reversal of expectations at $t=k=12$. In the rational model, by contrast, the price monotonically converges to $V$ from below.

\footnotetext{
${ }^{12}$ In BGMS (2018), the estimated signal to noise ratio of the average macroeconomic series was between 3.5 and 4 . In the current setting, this should be compared to the precision $\frac{\sigma_{\epsilon}}{V \sqrt{\tau}}$ of the signals received by the traders over some natural time scale $\tau$. Picking this time scale to be around $k$, we get $\sigma_{\epsilon}$ between 12 and 14 .
} 
Figure 1. Average Price Path

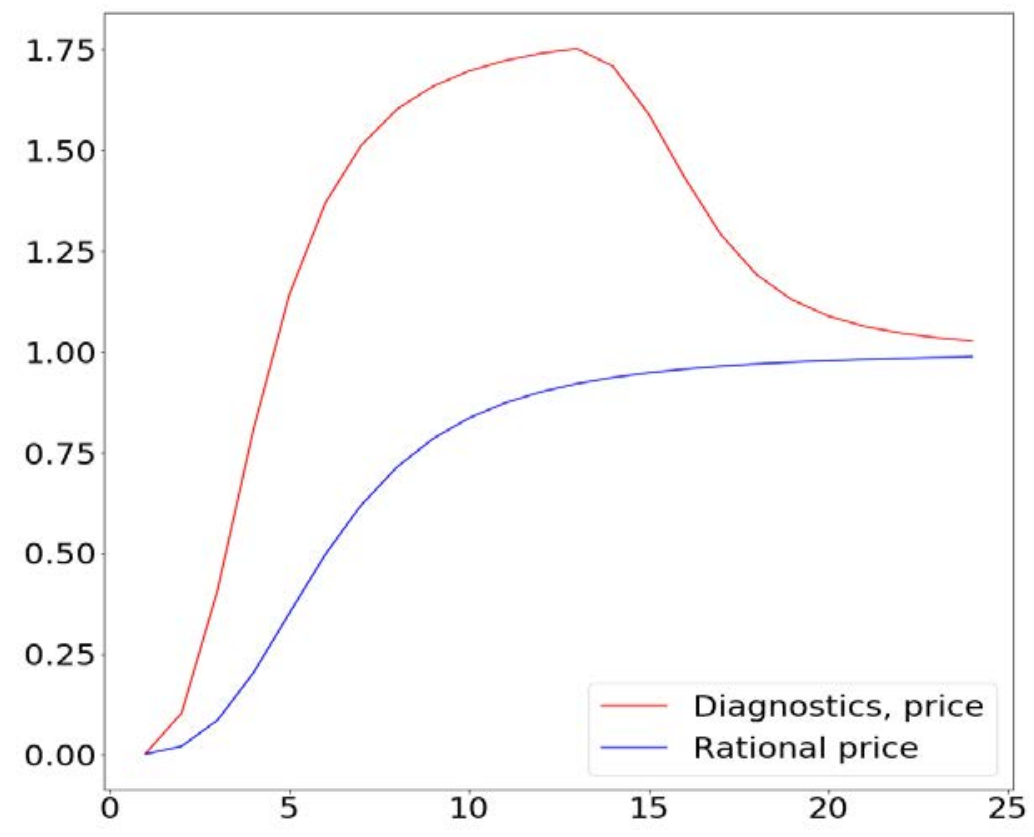

Rational expectations cannot produce over-reaction and price inflation because they constrain assessed fundamentals to always stay between the prior of zero and the true value $V$. The same is true under overconfidence, which can generate bubbles only in the presence of short sales constraints (Harrison and Kreps 1978). In our model, a displacement drives continued good news, resulting in a price boom. This leads traders to focus on the right tail of $V$ and think that the innovation is truly exceptional, causing prices to overreact.

The bust occurs at time $t=k+1$, when investors adapt to the displacement, starting to view the innovative asset or technology as the new norm. Here the length $k$ of the boom phase is deterministic, but the model could be made more realistic by having $k$ stochastic (and even heterogeneous across investors). As in the analysis of Proposition 1, adaptation to early news causes excess optimism to run out of steam, generating the bust. Reversal of expectations and prices due to disappointment of prior optimism can help account for the slowdown of some bubbles, but it is not the only mechanism behind a bust; other factors including bad news (the housing bubble deflating from 2006 onward), as well as the proximity of a terminal trading date (crucial in experimental findings), are surely significant. We consider the latter mechanism in Section 4.

Because traders observe independent signals, they have heterogeneous beliefs about the value of the asset. This creates room for disagreement and trading (Scheinkman and Xiong 2003). Barberis et al. (2018) show that disagreement tends to rise in the boom phase. Our model can create very similar effects. As time 
goes by, traders become more confident in their information, which causes them to place stronger weight on private signals. This effect tends to foster disagreement. At some point, the common price shock becomes so strong that disagreement declines. We plot the standard deviation of individual beliefs in Figure 2: disagreement rises in the early part of the boom, but falls as the public signal dominates the private information.

Figure 2. Model-Implied Belief Dispersion

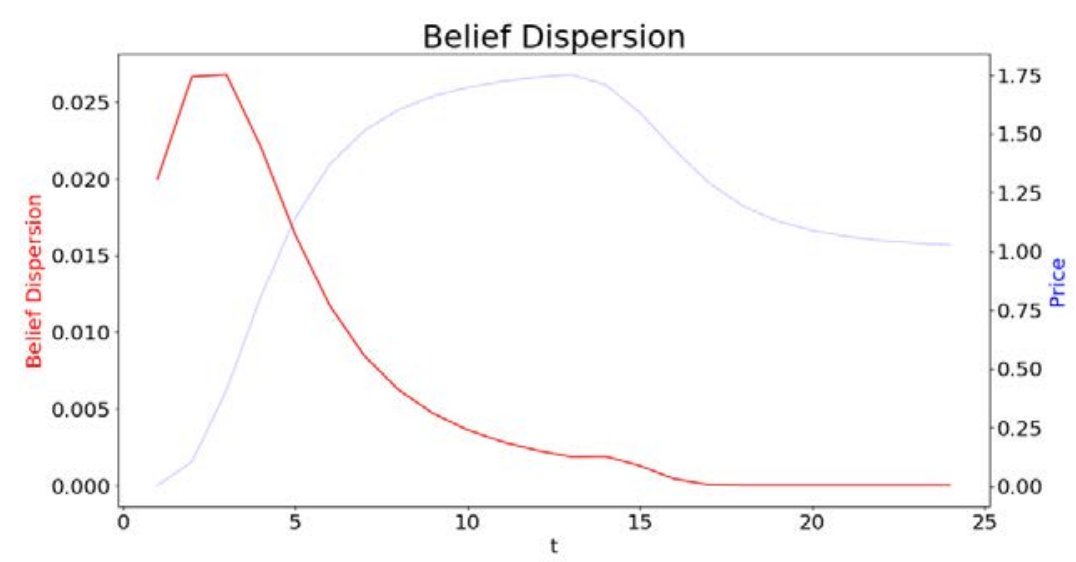

We can also use simulations to describe the dynamics of expectations of future prices. Under mechanical extrapolation, traders project past price increases into the future using the updating rule:

$$
\mathbb{E}_{t}\left(p_{t+1}\right)=p_{t}+\beta\left(p_{t-1}-p_{t}\right)
$$

where $\beta>0$ captures the fixed degree of price extrapolation. In our model, in contrast, traders watch prices in order to infer fundamentals. As a result, price extrapolation arises because high past prices signal high fundamentals and hence even higher future expected prices.

In Hong and Stein (1999), extrapolation is due to under-reaction, which makes it optimal for momentum traders to chase the upward trend in prices. In that model, momentum traders form expectations of future price changes by running simple univariate regressions of current on past price growth. In Glaeser and Nathanson (2017), investors believe that the price reflects fundamental value. An increase in price is then interpreted as stronger fundamentals, and leads to extrapolation of high prices into the future. In both models, as in adaptive expectations, extrapolation is due to the use of simplified (or wrong) models.

This logic suggests a testable difference between mechanical extrapolation models and price learning under diagnostic expectations. In the latter case, price extrapolation is the product of an inference process, 
distorted by $\theta$. This implies that the degree of extrapolation is not constant over time, but rather depends on the degree of uncertainty concerning fundamentals. In terms of Equation (13), our model predicts that the updating coefficient $\beta$ should not be constant, but depends on the extent to which prices are informative. Modest price increases observed in the early stages of a bubble are not very informative about the magnitude of the fundamental, so the coefficient $\beta$ should be low. In contrast, a sustained price increase (as observed some time into the bubble) is a solid indicator of a strong fundamental, and should therefore be associated with a much higher over-reaction, as measured by the coefficient $\beta$ under diagnostic expectations.

We evaluate these ideas by simulating the model. We run regression (13) using a time series of the model simulated using the parameters above. We produce 2000 such time series and plot in Figure 3 the histogram of estimated coefficients for both the diagnostic and the rational model.

Figure 3. Model-Implied Extrapolation Coefficient

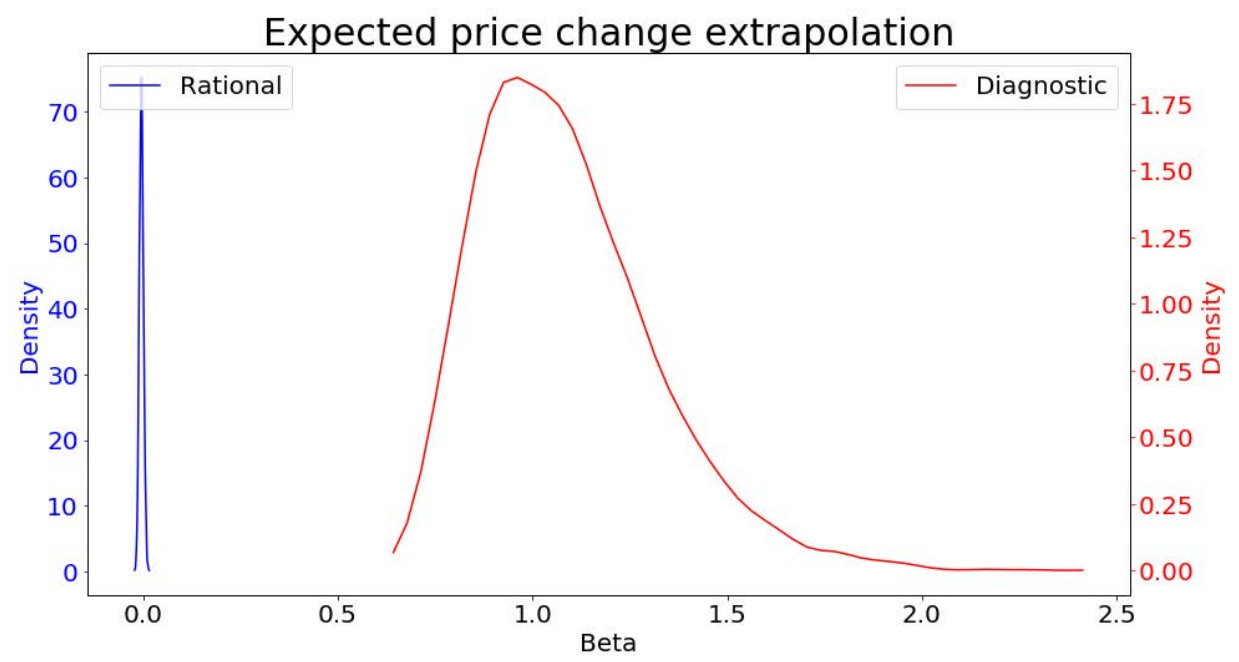

The coefficient of price extrapolation implied by the model is positive, between .5 and 1.5. Even though our investors are entirely forward looking, they appear to mechanically extrapolate past prices. This is not the case under rational expectations, where the coefficient is negative because traders discount their information and under-predict the future consensus (and hence price).

While diagnostic expectations entail a positive extrapolation coefficient on average across the entire bubble episode (as does mechanical extrapolation), the extrapolation coefficient is the highest when prices are most informative, namely close to the peak of the bubble. Figure 4 reports the average estimates of the 
extrapolative coefficient $\beta$ in each of six buckets, capturing growth, overshooting and collapse of the bubble. ${ }^{13}$ The results confirm our intuition: price extrapolation is strongest in the making of the bubble when there is rapid learning (the first phase highlighted in blue). This occurs because prices are most informative (relative to the private signal) in that range, which induces diagnostic traders to update upward more aggressively after a price rise. At the peak of the bubble, expectations of future prices are significantly above actual prices. After the bubble bursts, traders adjust their expectations downwards significantly, but not fast enough to converge to the actual prices. Thus, in this period extrapolation appears negative. Finally, as learning subsides, extrapolation goes to zero, just as in the rational case.

\section{Figure 4. Time-Dependent Extrapolation}

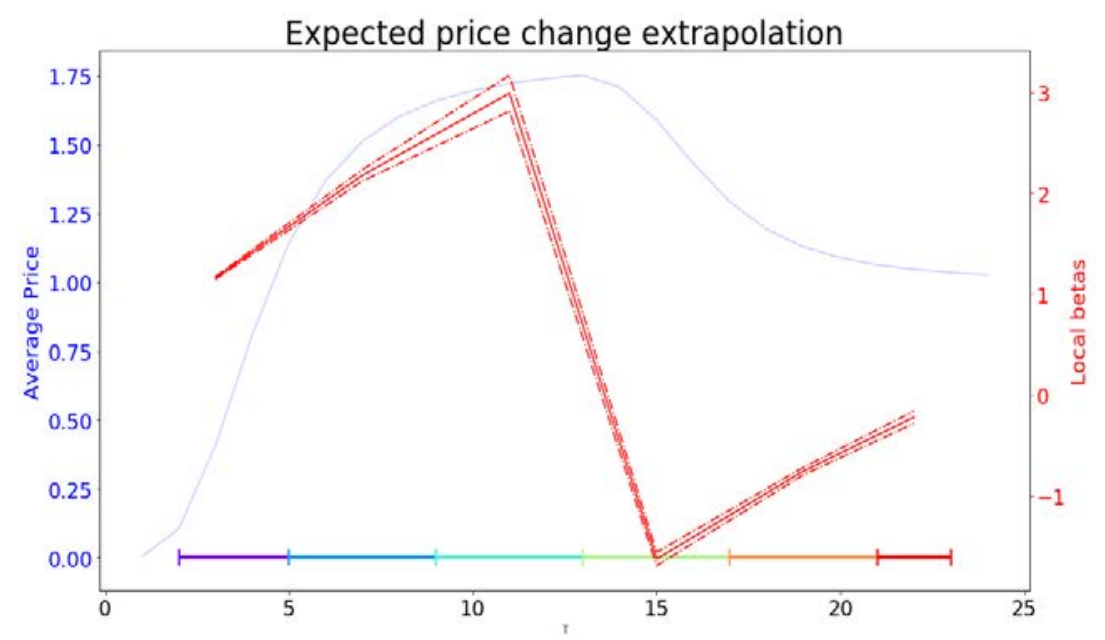

As Figures 3 and 4 show, this model can produce some price convexity and moderate overvaluation. However, this model precludes large bubbles because for reasonable values of $\theta$ prices are tethered to the longterm liquidation value. In contrast, prices sometimes strongly overshoot sensible measures of fundamentals. Second, while learning from prices generates some convexity in the price path, it does not create enough acceleration to generate increasing growth rate of prices (accelerating returns) seen in the data (Greenwood, Shleifer, and You 2018). We next show that both features can be attained by adding speculation to our model.

\footnotetext{
${ }^{13}$ To build Figure 3, we simulate 5000 price paths and expected future price paths. We pool simulations and compute the regression $\mathbb{E}_{t}\left(p_{t+1}\right)=p_{t}+\beta\left(p_{t}-p_{t-1}\right)$ within buckets of 4 time periods. Figure 3 reports the resulting $\beta \mathrm{s}$ and corresponding confidence intervals (running regressions for individual paths and averaging the $\beta$ s yields similar results).
} 


\section{Speculation}

To introduce speculation, we assume that traders have short horizons in the sense that their objective function at each time $t$ is to resell the asset at time $t+1$. The trading game lasts for $T$ rounds, and the traders holding the asset in the terminal date receive its fundamental value. We take $T$ to be exogenously given and deterministic, as in laboratory experiments of bubbles. In real markets, there is no such thing as a terminal date, but taking a fixed $T$ is a very convenient approximation to a setting in which there is a certain probability that at some point the "speculation game" ends in the sense that most traders attend to fundamentals.

With speculation, diagnostic expectations generate price paths with significantly larger overvaluation than in the previous models, followed by a price collapse as the terminal date approaches. This occurs because diagnostic speculators not only overreact to good fundamental news, but also expect to resell to overreacting buyers in the future, which drives the price today higher. As the terminal date approaches, the prospects for re-trading fade and the bubble bursts. These dynamics are very different from those obtained under rationality.

As in previous Sections, traders hold mean-variance preferences (in particular, expectations are normal in the diagnostic equilibrium). Away from the terminal date, $t<T$, trader $i$ chooses demand $D_{i t}$ to maximize $\left[\mathbb{E}_{i t}\left(p_{t+1}\right)-p_{t}\right] D_{i t}-\frac{\gamma}{2} \operatorname{Var}_{t}\left(p_{t+1}\right) D_{i t}^{2}$, while his objective at time $T$ is fundamental-based as before. Demand in each period is then given by:

$$
\begin{gathered}
D_{i, t}=\frac{\left[\mathbb{E}_{i, t}^{\theta}\left(p_{t+1}\right)-p_{t}\right]}{\gamma \operatorname{Var}_{t}\left(p_{t+1}\right)}, \quad \text { for } t=1, \ldots, T-1, \\
D_{i, t}=\frac{\left[\mathbb{E}_{i, t}^{\theta}(V)-p_{t}\right]}{\gamma \operatorname{Var}_{t}\left(p_{t+1}\right)}, \quad \text { for } t=T .
\end{gathered}
$$

With speculation, demand increases in the expected capital gain $\mathbb{E}_{i, t}^{\theta}\left(p_{t+1}\right)-p_{t}$ except in the last period $t=T$, in which traders buy the asset to hold it.

To illustrate the key consequences of speculation, we begin with a model in which there is no learning from prices. In Section 4.2 we then introduce such learning and compare this formulation to the one in Section 3. With learning from prices, we find a speculative equilibrium by again starting from a linear pricing function, 
which is then used to compute price expectations $\mathbb{E}_{i, t}^{\theta}\left(p_{t+1}\right)$ for next period. In each period, the coefficients of the pricing function are pinned down by equating demand and supply.

In both versions of the speculation model, speculation is itself a source of price reversal as $T$ approaches. We can thus simplify the analysis by assuming that the diagnostic reference is very sluggish, $k>$ $T$, so that information about the asset's value is always assessed compared to the prior $V=0$.

\subsection{Speculation without Learning from Prices}

Without learning from prices, we do not need a supply shock, so we assume that the supply of the asset is equal to zero. Aggregating the individual demand functions, prices are pinned down by the conditions:

$$
\begin{aligned}
& p_{t}=\int \mathbb{E}_{i, t}^{\theta}\left(p_{t+1}\right) d i, \quad \text { for } t=1, \ldots, T-1, \\
& p_{T}=\int \mathbb{E}_{i, T}^{\theta}(V) d i .
\end{aligned}
$$

In the final period $T$, the consensus fundamental value is $\mathbb{E}_{T}^{\theta}(V)=(1+\theta) \pi_{T} V$, as per Equation (3), leading to the terminal price $p_{T}=(1+\theta) \pi_{T} V$. Under the assumption $\theta \in\left(\frac{1}{T} \frac{\sigma_{\epsilon}^{2}}{\sigma_{v}^{2}}, \frac{\sigma_{\epsilon}^{2}}{\sigma_{v}^{2}}\right)$ of Proposition 1 , which we maintain, this price is above the fundamental, $(1+\theta) \pi_{T}>1 .^{14}$

Consider now the price at $T-1$. By Equation (16), this price is the consensus expectation as of $T-1$ of the terminal price $p_{T}$. To compute this consensus, consider first the expectation held at $T-1$ by a generic trader $j$. When forecasting the terminal price, this trader must make two assessments. First, he must assess the fundamental value $V$ of the asset. Second, he must assess how future traders will react to noisy signals of the same fundamental value. Because the beliefs of future traders are a random variable, trader $j$ uses the very same diagnostic formula of Equation (2) when representing their distribution. One can interpret this forecasting process in two ways. First, one can view trader $j$ as placing himself in the shoes of future traders

\footnotetext{
${ }^{14}$ Recall that in this Section we shut down the adaptation of diagnostic expectations by setting $k>T$.
} 
receiving different signals, predicting that these traders will behave the way he would behave in light of the same signals. Alternatively, one can view trader $j$ as forecasting the behavior of others understanding that they will update diagnostically. In both cases, we continue to rule out the possibility that any trader is sophisticated enough to be aware of his own diagnosticity, thereby correcting his assessments for it.

Consider how trader $j$ forecasts the beliefs at $T$ of a generic trader $i$ who has observed an average signal $\frac{\sum_{r=1}^{T} s_{i r}}{T}$ from the initial date to the terminal period. Trader $j$ knows that trader $i$ overreacts to all signals received, forming a terminal estimate $\mathbb{E}_{i T}^{\theta}(V)=(1+\theta) \pi_{T} \frac{\sum_{r=1}^{T} s_{i r}}{T}$. By averaging across all traders $i$, trader $j$ knows that, if the fundamental value is $V$, the consensus estimate, and hence the equilibrium price at $T$

$$
p_{T}=(1+\theta) \pi_{T} V
$$

This prediction is based on the fact that trader $j$ knows that, whichever signals observed by individual traders, they will average out to the true $V$. Of course, trader $j$ does not know the true value of $V$ at $T-1$; he only has an estimate of it, based on the signals $\frac{\sum_{r=1}^{T-1} s_{j r}}{T-1}$ observed up to that period. This estimate is diagnostic:

$$
\mathbb{E}_{j T-1}^{\theta}(V)=(1+\theta) \pi_{T-1} \frac{\sum_{r=1}^{T-1} s_{j r}}{T-1}
$$

The diagnostic expectation held at $T-1$ by trader $j$ about the terminal price is then given by:

$$
\begin{gathered}
\mathbb{E}_{j T-1}^{\theta}\left[\mathbb{E}_{T}^{\theta}(V)\right]=(1+\theta) \pi_{T} \mathbb{E}_{j T-1}^{\theta}(V) \\
=(1+\theta)^{2} \pi_{T} \pi_{T-1} \frac{\sum_{r=1}^{T-1} s_{j r}}{T-1} .
\end{gathered}
$$

This trader uses his signals but he compounds diagnosticity twice. First, he diagnostically overreacts to his signal, creating an inflated estimate of fundamentals. Second, he expects future traders to over-react to signals generated by the inflated fundamentals. To see the intuition, imagine that $j$ overestimates the share of future Googles in the population of tech firms to be $7 \%$. He then expects future traders to overreact relative his assessment and estimate the share of Googles to be, say, 10\%. In this way, overreaction to news compounds as the current forecast is projected into the future. 
Because every trader $j$ repeats the same logic, by averaging across all of them, the consensus forecast held at time $T-1$ about the terminal price, and thus the equilibrium price at $T-1$ is given by:

$$
p_{T-1}=(1+\theta)^{2} \pi_{T} \pi_{T-1} V .
$$

To gauge the role of diagnostic expectations, suppose that traders are rational, so $\theta=0$. In this case, the price at $T-1$ is lower than the terminal price, because $\pi_{T-1}<1$. As a result, under rationality speculation causes the price to rise as the terminal date is approached. It is well known that speculation under rationality leads to initial under-reaction, and thus to a rising price path (Allen et al. 2006). The intuition is that rational traders discount their signals and expect future traders to do the same. As a result, they do not expect to be able to resell the asset for a very high price, which keeps the current price low.

With diagnosticity, even a modicum of overreaction dramatically changes the calculus. When $\theta>0$, it is entirely possible that the price drops at the terminal date. This is true if and only if:

$$
p_{T-1}>p_{T} \Leftrightarrow(1+\theta) \pi_{T-1}>1 .
$$

If traders overestimate the fundamental value at time $T-1$, i.e. $(1+\theta) \pi_{T-1}>1$, then the price at $T-1$ is above both fundamentals and the terminal price. Indeed, by overestimating $V$, traders believe that future traders will overreact to this estimate, compounding overreaction twice. But then, the expectation to sell to these bullish traders in the future raises the current price of the asset.

In sharp contrast with the rational case, which leads to a monotone rising price path, diagnostic expectations introduce the opposite effect. By creating overreaction, they imply that prices decline toward the terminal date, reflecting an initial strong overvaluation of the asset.

To study the implications of $\theta>0$ fully, we need to iterate the same logic backward to earlier periods until the initial date $t=1$. It is immediate to see that the full path of equilibrium prices obtained by iterating Equation (18) backwards is described by:

$$
p_{t}=(1+\theta)^{T-t+1}\left[\prod_{r=t}^{T} \pi_{r}\right] V
$$

which implies the following result. 
Proposition 4 Define the geometric average of all signal to noise ratios $\hat{\pi} \equiv\left[\prod_{r=1}^{T} \pi_{r}\right]^{\frac{1}{T}}$. Then, if $\theta \in$ $\left(\frac{1}{T} \frac{\sigma_{\epsilon}^{2}}{\sigma_{v}^{2}}, \frac{1-\widehat{\pi}}{\widehat{\pi}}\right)$, where $\frac{1-\widehat{\pi}}{\widehat{\pi}}<\frac{\sigma_{\epsilon}^{2}}{\sigma_{v}^{2}}$, the speculative price dynamics exhibit the three bubble phases. In particular:

1. The price starts below fundamental, $p_{1}<V$, and gradually increases above fundamentals, reaching its maximum at the smallest time $\hat{t}$ for which $(1+\theta) \pi_{\hat{t}}>1$.

2. From $t=\hat{t}$ onwards the price monotonically declines toward $p_{T}$.

With diagnostic expectations, speculative dynamics can generate both the sluggish upward price adjustment typical of underreaction (provided $\theta$ is not too large), the price inflation relative to fundamentals typical of overreaction (provided $\theta$ is not too small), and the bust phase in which prices collapse, which here is driven by the reduction in the available rounds of reselling.

Because $(1+\theta) \hat{\pi}^{T}<1$, individual traders underreact to the aggregate information in the first period. The logic is the same as before: individual uncertainty about $V$ is still very large. Traders are not only cautious in estimating $V$, but also think that next period buyers will be cautious as well. This effect curtails the expected resale price and demand for the asset today, keeping its price low. As time goes by, traders acquire more information, become more confident, and start using it more aggressively. They become more optimistic about the signals future buyers will get, more confident about future buyers' over-optimism, and the price starts increasing. As traders gain confidence, the possibility of multiple rounds of reselling to over-reacting traders dramatically boosts price, which overshoots $V$. The price then starts declining as the terminal date $T$ approaches, because there are fewer and fewer rounds of trading and thus less scope for reselling to overreacting buyers.

Once again, under rationality, the dynamics of speculation do not yield a hump shaped price path. Given $\theta=0$, traders rationally anticipate that future traders will have lower signals than they do, and that they will in turn discount those signals, resulting in depressed prices. Because traders receive information over time, price grows monotonically and approaches $V$ from below. It displays momentum but not overshooting or reversal (Allen, Morris, and Shin 2006). 
Another important consequence of speculation is that it can greatly exacerbate the overshooting of fundamentals, relative to the benchmark model of Section 3. Equation (19) shows how speculation fuels bubbles under diagnostic expectations, and can cause strong price inflation even with small diagnostic distortions $\theta$. Consider the ratio of price under speculation to consensus expectations of fundamentals (which equals price in the absence of speculation). At the peak of the bubble, which occurs at $\hat{t}=\frac{1}{\theta} \frac{\sigma_{\epsilon}^{2}}{\sigma_{v}^{2}}$, this ratio is inflated relative to the rational benchmark as follows:

$$
\frac{p_{\hat{t}}(\theta)}{\mathbb{E}_{\hat{t}}^{\theta}(V)}=(1+\theta)^{T-\frac{1 \sigma_{\epsilon}^{2}}{\theta} \sigma_{v}^{2}} \frac{p_{\hat{t}}(0)}{\mathbb{E}_{\hat{t}}^{0}(V)}
$$

While under diagnostic expectations beliefs about fundamentals are inflated by a linear factor of $\theta$, namely $\frac{\mathbb{E}_{t}^{\theta}(V)}{\mathbb{E}_{\hat{t}}^{0}(V)}=1+\theta$, when speculation is included the inflation of price relative to beliefs grows as a power of $1+$ $\theta$. Even a small departure $\theta$ from rationality can fuel large bubbles. This much stronger growth reflects the compounding effect of over-optimism about selling to overreacting investors until the horizon $T$. Increasing $\theta$ increases optimism, which also implies that the peak of the bubble is reached earlier, which in turn implies a stronger compound effect of diagnostic expectations.

\subsection{Learning from Prices}

We now enrich the speculation model with learning from prices, which may further fuel speculative dynamics by leading traders to expect strong price appreciation following good fundamental news. Building on the analysis in Section 3, we start from the pricing rule of Equation (6), setting $a_{1 t}=0$ (which follows from our earlier analysis) as well as $a_{3 t}=0$, since for $k>T$ the lagged expectation is redundant. We reintroduce supply shocks to prevent prices from being fully revealing. Traders now use the pricing rule also to forecast future prices, not only to learn about $V$. Equations (16) and (17) then imply the following market clearing conditions:

$$
p_{t}=\int \mathbb{E}_{i, t}^{\theta}\left(p_{t+1}\right) d i-\gamma \operatorname{Var}_{t}\left(p_{t+1}\right) S_{t}, \quad \text { for } t=1, \ldots, T-1
$$




$$
p_{T}=\int \mathbb{E}_{i, T}^{\theta}(V) d i-\gamma \operatorname{Var}_{T}(V) S_{T}
$$

In line with Equation (9), the diagnostic expectation of value held by trader $i$ after observing the private signals $\left(s_{i 1}, \ldots, s_{i t}, s_{1}^{p}, \ldots s_{t}^{p}\right)$ is given by:

$$
\mathbb{E}_{i, t}^{\theta}(V)=(1+\theta)\left[\bar{s}_{i, t} z_{t}+\mathbb{E}_{t}(V \mid P)\left(1-z_{t}\right)\right]
$$

where $z_{t}=\frac{t}{\sigma_{\epsilon}^{2}}\left[\frac{t}{\sigma_{\epsilon}^{2}}+\frac{1}{\sigma_{p, t}^{2}(V)}\right]^{-1}$. Here $\sigma_{p, t}^{2}(V)$ denotes the variance of fundamentals at $t$ when there is learning only from prices. The diagnostic expectation of price and its variance are then equal to:

$$
\begin{aligned}
& \mathbb{E}_{i, t}^{\theta}\left(p_{t+1}\right)=(1+\theta)\left[a_{t+1} \mathbb{E}_{i, t}\left[\mathbb{E}\left(V \mid P_{t+1}\right)\right]+b_{t+1} \mathbb{E}_{i, t}(V)\right] \\
& \operatorname{Var}_{t}\left(p_{t+1}\right)=\left[a_{t+1}\left(1-\frac{\sigma_{p, t+1}^{2}(V)}{\sigma_{p, t}^{2}(V)}\right)+b_{t+1}\right]^{2} \operatorname{Var}_{t}\left(s_{t+1}^{p}\right) .
\end{aligned}
$$

By plugging these expressions in the market clearing conditions we show the following result.

Proposition 5. A diagnostic equilibrium at parameters $\left(\gamma, \theta, \sigma_{S}^{2}, \sigma_{\epsilon}^{2}, \sigma_{V}^{2}, T\right)$ is a set of coefficients $\left(a_{2, t}, b_{t}, c_{t}\right)_{t=1 \ldots, T}$ and price-based variance $V_{t}^{p}$ satisfying the recursion for $t<T$ :

$$
\begin{gathered}
b_{t}=(1+\theta) \frac{t}{\sigma_{\epsilon}^{2}} \frac{\left[\left[(1+\theta)^{T-t}-b_{t+1}\right]\left[\frac{1}{\sigma_{p, t+1}^{2}(V)}\right]^{-1}\left(\frac{b_{t+1}}{c_{t+1}}\right)^{2} \frac{1}{\sigma_{S}^{2}}+b_{t+1}\right]}{\left[\frac{t}{\sigma_{\epsilon}^{2}}+\frac{1}{\sigma_{p, t+1}^{2}(V)}-\left(\frac{b_{t+1}}{c_{t+1}}\right)^{2} \frac{1}{\sigma_{S}^{2}}\right]} \\
c_{t}=\gamma\left[\left[(1+\theta)^{T-t}-b_{t+1}=(1+\theta)^{T-t+1}-b_{t},\right.\right. \\
\left.\left.\left.+\left(\frac{c_{t+1}}{b_{t+1}}\right)^{2} \sigma_{S}^{2}\right], \frac{1}{\sigma_{p, t+1}^{2}(V)}\right]^{-1}\left(\frac{b_{t+1}}{c_{t+1}}\right)^{2} \frac{1}{\sigma_{S}^{2}}+b_{t+1}\right]^{2}\left[\left[\frac{t}{\sigma_{\epsilon}^{2}}+\frac{1}{\sigma_{p, t+1}^{2}(V)}-\left(\frac{b_{t+1}}{c_{t+1}}\right)^{2} \frac{1}{\sigma_{S}^{2}}\right]^{-1}\right. \\
\frac{1}{\sigma_{p, t}^{2}(V)}=\frac{1}{\sigma_{p, t+1}^{2}(V)}-\left(\frac{b_{t+1}}{c_{t+1}}\right)^{2} \frac{1}{\sigma_{S}^{2}}
\end{gathered}
$$


with terminal conditions:

$$
\begin{aligned}
& b_{T}=(1+\theta) \frac{T}{\sigma_{\epsilon}^{2}}\left[\frac{T}{\sigma_{\epsilon}^{2}}+\frac{1}{\sigma_{p, T}^{2}(V)}\right]^{-1} \\
& c_{T}=\gamma\left[\frac{T}{\sigma_{\epsilon}^{2}}+\frac{1}{\sigma_{p, T}^{2}(V)}\right]^{-1} \\
& \frac{1}{\sigma_{p, 0}^{2}(V)}=\frac{1}{\sigma_{V}^{2}} .
\end{aligned}
$$

The above iteration specifies values at $t$ as a function of those at $t+1$, so that the recursion identifies the equilibrium from the terminal condition.

Proposition 6. There exists $\sigma_{p, T}^{2}(V)$ such that condition (26) holds and the equilibrium exists.

Introducing learning from prices into the model with speculation adds some attractive features. Like in the model of Section 3, learning from prices leads to more aggressive price growth once the bubble starts, and to a peak price higher than that without learning from prices. To explore the model's properties, and to systematically compare it to the model without speculation, we turn to simulations.

\subsection{Model Simulations}

In this Section, we present simulations of the model with speculation and learning from prices, and compare it to the model of Section 3 in terms of its ability to generate price acceleration and large overvaluation. ${ }^{15}$ Using the same parameters as in Section 3.2, we compare the price paths that obtain when investors learn from prices, with and without speculation. To compute the price path under speculation, we first find the terminal variance $\sigma_{p, T}^{2}$ (from which previous $\sigma_{p, t}^{2}$ are computed in equilibrium) such that condition (26) holds, as described in Proposition 5.

\footnotetext{
${ }^{15}$ Here we do not consider price extrapolation because, when every investor is a speculator, expectations of future prices are embedded in current prices. The current setting thus misses the "partial equilibrium” perspective in which the current price does not yet contain information available to the investor expressing price beliefs. One way to assess price extrapolation in this context is to have a market consisting of both fundamental investors and speculators (with both types learning from prices). We leave this interesting exercise for future work.
} 
Figure 5 plots the average price path prevailing when the supply shock $S_{t}$ is zero in all periods. For comparison, it also plots the corresponding path of expectations about fundamentals under speculation. Several features stand out. First, the price path displays the three phases described by Kindelberger (1978), namely a price growth phase, an acceleration and overshooting phase, and then a collapse. Second, the first phase is protracted, with prices being lower than in the rational case at first, before they accelerate. At this stage, speculative motives slow down learning from the prices. Third, when prices accelerate, they do so much more strongly than in the absence of speculation, and the extent of overpricing is much greater than that obtained in the previous model with the same parameters.

Figure 5. Speculation and learning from prices

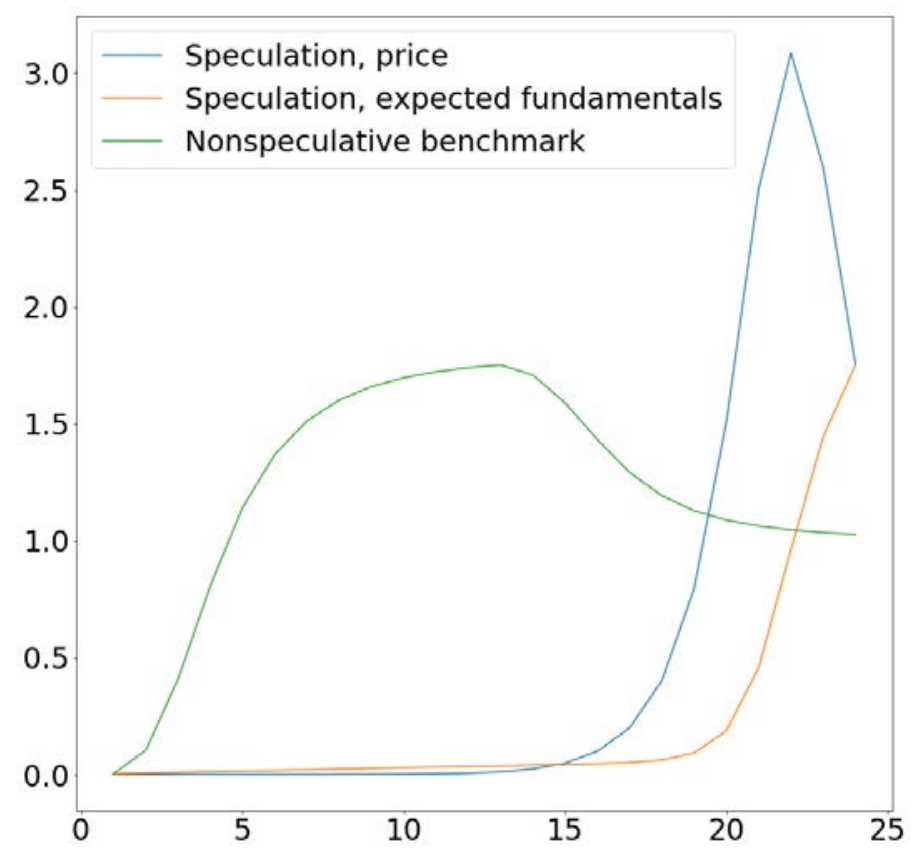

These features are driven by the interaction of speculation with learning from prices. The speculative motive adds uncertainty to the prices, but also allows traders to trade more aggressively on their beliefs. These forces play a differential role throughout the bubble episode. At first, traders have little information and prices are less informative about fundamentals. Traders thus heavily discount early price increases, which may be driven by a supply shock compounded by the willingness to speculate of other traders. Because all traders behave this way, prices (and beliefs about $V$ ) remain low. In this phase, speculation compounds under-reaction and the price path is similar to what would be obtained under rationality. However, once individual traders are confident that the innovation is in fact valuable, the interaction reverses sign. At this point, price paths under 
diagnostic and rational expectations become very different. With diagnostic expectations, learning from prices fuels speculation, because current prices convey more information, and the price skyrockets above fundamentals. As the terminal date $T$ approaches, the extent of possible reselling decreases and so the price drops. This boom-bust pattern is not possible under rationality, which entails a monotonically increasing price that converges to $V$ from below.

In sum, the current model exhibits both fast growth of prices as well as very strong overvaluation within a set of parameters broadly consistent with data on expectations and with the duration of the different phases of several bubble episodes. Speculation under diagnostic expectations plays a key role by capturing the idea - present in Kindleberger (1978) and other analyses of bubbles - of optimistic investors bidding up prices with the expectation of selling subsequently to other, even more optimistic, investors. This mechanism helps the model generate substantial bubbles even when the departure from rationality is modest. A degree of distortions of $\theta=0.8$ generates in the above simulation a price peak that is three times the fundamental, and about $80 \%$ higher than the price peak in the absence of speculation. Mechanical price extrapolation is not necessary to generate such overpricing. The role of Kindelberger's fundamental displacement in generating bubbles may be larger than usually thought.

\section{Conclusion}

In this paper, we brought a micro-founded model of beliefs, diagnostic expectations, to the problem of modeling bubbles. We have considered two formulations: belief formation about fundamentals with learning from prices and also speculation, whereby investors focus on reselling the asset next period. We showed that both of these formulations exhibit the central features of bubbles as conceived by Kindleberger (1978): displacement, price acceleration, and a crash. Moreover, these models deliver extrapolative beliefs and overreaction to information during the later stages of the bubble that are so central both to the Kindleberger narrative and empirical facts about bubbles.

Our micro-founded model of beliefs, based on expectations about fundamentals, delivers two further insights into the anatomy of bubbles. First, it connects over-reaction to fundamental news, which is the central 
implication of diagnostic expectations, to price extrapolation, which has been increasingly seen as a key feature of bubbles (see Barberis et al. 2018). In our model, price extrapolation is far from constant over the course of the bubble, as in mechanical models of adaptive expectations, but in fact emerges as a byproduct of diagnostic expectations during the rapid price growth stage of the bubble. In fact, the bubble collapses in part because the psychological mechanisms that entail price extrapolation run out of steam.

Second, our model illustrates the centrality of speculation for bubbles. Bubbles exist in specifications where traders focus on the final liquidation value of the asset. But bubbles are much more dramatic when traders focus on the resale next period because their valuations are no longer tethered to liquidation values, and they bid up the asset's price based on the expectation of other trader's optimism next period. Indeed, we show that in a model with speculation, but not otherwise, even a small amount of diagnosticity in belief formation can lead to extremely large overvaluation during the rapid growth stage of the bubble. Even a mild departure from rational expectations, when combined with speculation, can entail extreme overvaluation.

These insights into the structure of asset price bubbles would not be obtained without modeling beliefs explicitly from fundamental psychological assumptions, and combining this with standard neoclassical mechanisms, such as learning from prices and speculation. But while this approach advances our understanding of the anatomy of price bubbles, it is only a first step. We have not considered further critical features of price bubbles, emphasized by Kindleberger but also obviously critical to the financial crisis of 2008 as well as other crises (Gennaioli and Shleifer 2018). These include leverage as well as the central involvement of banks and other financial institutions in the bubble episode. Introducing these elements into a model of bubbles with diagnostic expectations would get us closer to understanding the structure of financial fragility, beginning with basic features of expectations. 


\section{References}

Alesina, Alberto, Armando Miano, and Stefanie Stantcheva. 2018. “Immigration and Redistribution,” NBER Working Paper no. 24733.

Allen, Franklin, Stephen Morris, and Hyun Song Shin. 2006. "Beauty Contests and Iterated Expectations in Asset Markets.” Review of Financial Studies 19 (3): 719-752.

Arnold, David, Will Dobbie and Crystal Yang. 2018. “Racial Bias in Bail Decisions,” Quarterly Journal of Economics 133 (4): 1885-1932.

Bagehot, Walter. 1873. Lombard Street: A Description of the Money Market. New York: Wiley.

Barberis, Nicholas, Robin Greenwood, Lawrence Jin, and Andrei Shleifer. 2015. “X-CAPM: An Extrapolative Capital Asset Pricing Model,” Journal of Financial Economics 115 (1): 1-24.

Barberis, Nicholas, Robin Greenwood, Lawrence Jin, and Andrei Shleifer. 2018. "Extrapolation and Bubbles,” Journal of Financial Economics 129 (2): 203-227.

Barberis, Nicholas, and Andrei Shleifer. 2003. “Style Investing.” Journal of Financial Economics 68 (2): 161-199.

Barsky, Robert and Bradford De Long. 1993. “Why Does the Stock Market Fluctuate?” Quarterly Journal of Economics 108 (2): 291-311.

Black, Fischer. 1986. “Noise,” Journal of Finance 41 (3): 528-543.

Blanchard, Olivier and Mark Watson. 1982. "Bubbles, Rational Expectations and Financial Markets,” in Crises in the Economic and Financial Structure, Paul Wachtel, editor, 296-316.

Bordalo, Pedro, Katherine Coffman, Nicola Gennaioli, and Andrei Shleifer. 2016. “Stereotypes,” Quarterly Journal of Economics 131 (4): 1753-1794.

Bordalo, Pedro, Katherine Coffman, Nicola Gennaioli, and Andrei Shleifer. 2018. "Beliefs about Gender,” American Economic Review, forthcoming.

Bordalo, Pedro, Nicola Gennaioli, and Andrei Shleifer. 2018. "Diagnostic Expectations and Credit Cycles,” Journal of Finance 73 (1): 199-227.

Bordalo, Pedro, Nicola Gennaioli, Rafael La Porta, and Andrei Shleifer. 2018. "Diagnostic Expectations and Stock Returns,” Journal of Finance, forthcoming.

Bordalo, Pedro, Nicola Gennaioli, Yueran Ma, and Andrei Shleifer. 2018. “Over-reaction in Macroeconomic Expectations,” NBER Working Paper no. 24932.

Case, Karl and Robert Shiller. 2003. “Is There a Bubble in the Housing Market?” Brookings Papers on Economic Activity, 2: 299-362.

Case, Karl E., Robert J. Shiller, and Anne K. Thompson. 2012. "What Have They Been Thinking? Homebuyer Behavior in Hot and Cold Markets.” Brookings Papers on Economic Activity 45: 265-315.

Cutler, David M., James M. Poterba, and Lawrence H. Summers. 1990. "Speculative Dynamics and the Role of Feedback Traders.” American Economic Review Papers and Proceedings 80 (2): 63-68.

Daniel, Kent, David Hirshleifer, and Avanidhar Subrahmanyam. 1998. "Investor Psychology and Security Market Under- and Over-Reactions.” Journal of Finance 53 (6): 1839-1885.

DeFusco, Anthony, Charles Nathanson, and Eric Zwick. 2018. "Speculative Dynamics of Prices and Volume,” NBER Working Paper no. 23449. 
DeLong, Bradford, Andrei Shleifer, Lawrence Summers, and Robert Waldmann. 1990a. "Noise Trader Risk in Financial Markets,” Journal of Political Economy 98 (4): 703-738.

DeLong, Bradford, Andrei Shleifer, Lawrence Summers, and Robert Waldmann 1990b. "Positive Feedback Investment Strategies and Destabilizing Rational Speculation,” Journal of Finance 45 (2): 379-395.

Fama, Eugene. 2014. “Two Pillars of Asset Pricing,” American Economic Review 104 (6): 1467-1485.

Galbraith, John K. 1954. The Great Crash: 1929. Houghton Mifflin Co., Boston, MA.

Gennaioli, Nicola, and Andrei Shleifer. 2010. "What Comes to Mind,” Quarterly Journal of Economics 125 (4): 1399-1433.

Gennaioli, Nicola, and Andrei Shleifer. 2018. A Crisis of Beliefs: Investor Psychology and Financial Fragility, Princeton, NJ: Princeton University Press.

Gennaioli, Nicola, Andrei Shleifer, and Robert Vishny. 2012. "Neglected Risks, Financial Innovation, and Financial Fragility.” Journal of Financial Economics 104 (3): 452-68.

Giglio, Stefano, Matteo Maggiori, and Johannes Stroebel. 2016. "No-Bubble Condition: Model-Free Tests in Housing Markets,” Econometrica 84 (3): 1047-1091.

Glaeser, Edward, Joseph Gyourko, and Albert Saiz. 2008. “Housing Supply and Housing Bubbles,” Journal of Urban Economics 64 (2): 198-217.

Glaeser, Edward, and Charles Nathanson. 2017. “An Extrapolate Model of House Price Dynamics,” Journal of Financial Economics 126 (1): 147-170.

Greenwood, Robin, and Samuel G. Hanson. 2014. “Waves in Ship Prices and Investment,” Quarterly Journal of Economics 130 (1): 55-109.

Greenwood, Robin, and Andrei Shleifer. 2014. "Expectations of Returns and Expected Returns,” Review of Financial Studies 27 (3): 714-746.

Greenwood, Robin, Andrei Shleifer, and Yang You. 2018. "Bubbles for Fama,” Journal of Financial Economics 130 (1): 20-43.

Grossman, Sanford. 1976. "On the Efficiency of Competitive Stock Markets where Trades have Diverse Information,” Journal of Finance 31 (2): 573-585.

Grossman, Sanford and Joseph Stiglitz. 1980. “On the Impossibility of Informationally Efficient Markets,” American Economic Review 70 (3): 393-408.

Grossman, Sanford and Merton Miller. 1988. “Liquidity and Market Structure,” Journal of Finance 43 (3): 617-633.

Harrison, Michael, and David Kreps. 1978. "Speculative Investor Behavior in a Stock Market with Heterogenous Expectations,” Quarterly Journal of Economics 92 (2): 323-336.

Haruvy, Ernan, Yaron Lahav, and Charles N. Noussair. 2007. “Traders' Expectations in Asset Markets: Experimental Evidence.” American Economic Review 97 (5): 1901-1920.

Hirshleifer, David, Jun Li, and Jianfeng Yu. 2015. “Asset Pricing in Production Economies with Extrapolative Expectations.” Journal of Monetary Economics 76 (2015): 87-106.

Hong, Harrison, and Jeremy C. Stein. 1999. "A Unified Theory of Underreaction, Momentum Trading, and Overreaction in Asset Markets.” Journal of Finance 54 (6): 2143-84.

Hong, Harrison, and Jeremy C. Stein. 2007. "Disagreement and the Stock Market.” Journal of Economic Perspectives 21 (2): 109-128. 
Jorda, Oscar, Moritz Schularick, and Alan Taylor. 2015. “Leveraged Bubbles,” Journal of Monetary Economics 76S: 1-20.

Kahneman, Daniel, and Amos Tversky. 1972. "Subjective Probability: A Judgment of Representativeness,” Cognitive Psychology 3 (3): 430-454.

Kahneman, Daniel, and Amos Tversky. 1983. "Extensional versus Intuitive Reasoning: The Conjunction Fallacy in Probability Judgment.” Psychological Review 90 (4): 293-315.

Kindleberger, Charles. 1978. Manias, Panics, and Crashes: A History of Financial Crises, New York: Basic Books.

La Porta, Rafael. 1996. "Expectations and the Cross-Section of Stock Returns.” Journal of Finance 51 (5): 1715-42.

Lakonishok, Josef, Andrei Shleifer, and Robert W. Vishny. 1994. "Contrarian Investment, Extrapolation, and Risk.” Journal of Finance 49 (5): 1541-78.

Mackay, Charles. 1841. Extraordinary Popular Delusions and the Madness of Crowds. New York: Harmony Books.

Martin, Alberto and Jaume Ventura. 2012. "Economic Growth with Bubbles.” American Economic Review 102 (6): 3033-58.

Mian, Atif, and Amir Sufi. 2014. House of Debt: How They (and You) Caused the Great Recession, and How We Can Prevent It from Happening Again. Chicago, IL: University of Chicago Press.

Mian, Atif, and Amir Sufi. 2018. "Finance and Business Cycles: The Credit-Driven Household Demand Channel,” Journal of Economic Perspectives 32 (3): 31-58.

Pastor, Lubos and Pietro Veronesi. 2006. “Was There a Nasdaq Bubble in the Late 1990s?” Journal of Financial Economics 81 (1): 61-100.

Pastor, Lubos and Pietro Veronesi. 2009. “Technological Revolutions and Stock Prices,” American Economic Review 99 (4): 1451-1483.

Reinhart, Carmen M., and Kenneth S. Rogoff. 2009. This Time Is Different: Eight Centuries of Financial Folly. Princeton, NJ: Princeton University Press.

Scheinkman, José and Wei Xiong. 2003. “Overconfidence and Speculative Bubbles,” Journal of Political Economy 111 (6): 1183-1220.

Shiller, Robert J. 2000. Irrational Exuberance. Princeton, NJ: Princeton University Press.

Shiller, Robert. 2015. Irrational Exuberance, 3rd edition. Princeton, NJ: Princeton University Press.

Smith, Vernon, Gerry Suchanek, and Arlington Williams. 1988. "Bubbles, Crashes, and Endogenous Expectations in Experimental Spot Asset Markets,” Econometrica 56 (5): 1119-1151.

Tirole, Jean. 1985. “Asset Bubbles and Overlapping Generations.” Econometrica 53 (5): 1071-1100.

Woodford, Michael. 2003. "Imperfect Common Knowledge and the Effects of Monetary Policy,” in Knowledge, Information and Expectations in Modern Macroeconomics: In Honor of Edmund S. Phelps, edited by P. Aghion, R. Frydman, J. Stiglitz, and M. Woodford, 25-58. Princeton, NJ: Princeton Univ. Press. 


\section{Appendix: Proofs.}

Lemma 1. At time $t$, each trader has access to $t$ signals of precision $\frac{1}{\sigma_{\epsilon}^{2}}$, as well as a prior with precision $\frac{1}{\sigma_{V}^{2}}$ around 0. By standard results in normal posterior updating, the trader's rational posterior is a normal distribution, with the following mean and variance.

$$
\begin{gathered}
\mathbb{E}_{i, t}(V)=\frac{t / \sigma_{\epsilon}^{2}}{t / \sigma_{\epsilon}^{2}+1 / \sigma_{V}^{2}} \overline{s_{l, t}}=\pi_{t} \bar{s}_{i t} \\
\sigma_{t}^{2}(V)=\frac{1}{\frac{t}{\sigma_{\epsilon}^{2}}+\frac{1}{\sigma_{V}^{2}}}=\left(1-\pi_{t}\right) \sigma_{V}^{2}
\end{gathered}
$$

The diagnostic distribution then reads (up to normalization constants):

$$
\exp \left\{-\frac{1}{2 \sigma_{t}^{2}(V)}\left[\left(V-\mathbb{E}_{i, t}(V)\right)^{2}(1+\theta)-\theta\left(V-\mathbb{E}_{i, t-1}(V)\right)^{2}\right]\right\}
$$

The quadratic and linear terms in $V$ are given by (the constant terms are absorbed by normalization):

$$
\exp \left\{-\frac{1}{2 \sigma_{t}^{2}(V)}\left[V^{2}-2 V\left(\mathbb{E}_{i, t}(V)(1+\theta)-\theta \mathbb{E}_{i, t-1}(V)\right)\right]\right\}
$$

It follows that the diagnostic distribution is also a normal $\mathcal{N}\left(\mathbb{E}_{i, t}^{\theta}(V), \operatorname{Var}_{t}^{\theta}(V)\right)$ with mean:

$$
\mathbb{E}_{i, t}^{\theta}(V)=\mathbb{E}_{t}(V)+\theta\left[\mathbb{E}_{i, t}(V)-\mathbb{E}_{i, t-1}(V)\right]
$$

and variance:

$$
\left(\sigma_{t}^{\theta}\right)^{2}(V)=\sigma_{t}^{2}(V)
$$

from which the result follows.

Proposition 1. For simplicity, denote $\alpha=\frac{\sigma_{\epsilon}^{2}}{\sigma_{V}^{2}}$. The price is then $p_{t}=\frac{t}{t+\alpha} V$ for $t \leq k$. Note that the price function is increasing from $t=1$ to $k$. Next, let us show that $p_{k+1}<p_{k}$. It suffices to show:

$$
\begin{aligned}
& \frac{(1+\theta) k}{k+\alpha}>\frac{(1+\theta)(k+1)}{k+1+\alpha}-\frac{\theta}{1+\alpha} \\
& \Leftrightarrow \theta>\frac{\alpha}{k} \cdot \frac{\alpha+1}{k+2 \alpha+1}
\end{aligned}
$$


As we have assumed that $\theta \in\left(\frac{1}{k} \frac{\sigma_{\epsilon}^{2}}{\sigma_{v}^{2}}, \frac{\sigma_{\epsilon}^{2}}{\sigma_{v}^{2}}\right)=\left(\frac{1}{k} \alpha, \alpha\right)$, the above inequality is satisfied.

Next, we show that prices are decreasing after $t=k$ until it hits the trough. Taking the derivative of the price with respect to $t$, one obtains:

$$
\frac{d p}{d t}=\frac{(1+\theta) \alpha}{(t+\alpha)^{2}} V-\frac{\theta \alpha}{(t-k+\alpha)^{2}}
$$

The above expression is negative if and only if:

$$
\frac{d p}{d t}<0 \Leftrightarrow\left(\frac{t+\alpha}{t-k+\alpha}\right)^{2}<\frac{\theta}{1+\theta} \Leftrightarrow t<\left(1-\sqrt{\frac{\theta}{1+\theta}}\right)^{-1} \cdot k-\alpha=k \cdot\left[\left(1-\sqrt{\frac{\theta}{1+\theta}}\right)^{-1}-\frac{\alpha}{k}\right]
$$

Finally, after $t^{*} \equiv k \cdot \max \left[1,\left\lfloor\left(1-\sqrt{\frac{\theta}{1+\theta}}\right)^{-1}-\frac{\alpha}{k}\right]\right]$, the price increases monotonically. To conclude, observe that $\left[\pi_{t}+\theta\left(\pi_{t}-\pi_{t-k}\right)\right] V \mapsto V$, because $\pi_{t} \mapsto 1$ as $t \mapsto \infty$.

Proposition 2. We start by assuming a linear price formula of the form:

$$
p_{t}=a_{2 t} \mathbb{E}\left(V \mid P_{t}\right)++b_{t}\left(V-\frac{c_{t}}{b_{t}} S_{t}\right)
$$

for $t \leq k$. Denote $s_{t}^{p}=\frac{1}{b_{t}}\left(p_{t}-a_{t 2} E\left[V \mid P_{t}\right]\right)=V-\frac{c_{t}}{b_{t}} S_{t}$ as the public signal obtained about $V$ from the prices. Furthermore, let $\zeta_{t}$ be the precision of the public distribution, i.e. $\zeta_{t}=\frac{1}{\sigma_{p, t}^{2}}$, and use the shorthand $E_{t}^{p}=$ $E\left[V \mid P_{t}\right]$. Using standard results of normal posteriors, we obtain:

$$
\begin{aligned}
& E_{t}^{p}=\frac{1}{\sigma_{S}^{2}} \sum_{r=1}^{t-1} s_{r}^{p}\left(\frac{b_{r}}{c_{r}}\right)^{2} \frac{1}{\zeta_{t}} \\
& \zeta_{t}=\frac{1}{\sigma_{V}^{2}}+\frac{1}{\sigma_{S}^{2}} \sum_{r=1}^{t-1}\left(\frac{b_{r}}{c_{r}}\right)^{2}
\end{aligned}
$$

Denoting $\overline{E_{t}}$ as the average rational fundamental beliefs, it follows that:

$$
\bar{E}_{t}=\int\left[\frac{1}{\sigma_{V}^{2}}+\frac{1}{\sigma_{S}^{2}} \sum_{r=1}^{t-1} s_{r}^{p}\left(\frac{b_{r}}{c_{r}}\right)^{2}\right] \frac{1}{\zeta_{t}} d i=\frac{\frac{t}{\sigma_{\epsilon}^{2}}}{\frac{t}{\sigma_{\epsilon}^{2}}+\zeta_{t}} V+\frac{\zeta_{t}}{\frac{t}{\sigma_{\epsilon}^{2}}+\zeta_{t}} E_{t}^{p}
$$

Then, as $t \leq k$, we have ${\overline{E_{t}}}^{\theta}=(1+\theta) \bar{E}_{t}$, and hence our equilibrium condition

$$
p_{t}={\overline{E_{t}}}^{-\theta}-\gamma \sigma_{t}^{2}(V) S_{t}
$$


translates to:

$$
p_{t}=(1+\theta)\left(\frac{\frac{t}{\sigma_{\epsilon}^{2}}}{\frac{t}{\sigma_{\epsilon}^{2}}+\zeta_{t}} V+\frac{\zeta_{t}}{\frac{t}{\sigma_{\epsilon}^{2}}+\zeta_{t}} E_{t}^{p}\right)-\gamma \frac{S_{t}}{\frac{t}{\sigma_{\epsilon}^{2}}+\zeta_{t}}
$$

Matching coefficients, we obtain:

$$
\begin{aligned}
& a_{2 t}=(1+\theta) \frac{\zeta_{t}}{\frac{t}{\sigma_{\epsilon}^{2}}+\zeta_{t}} \\
& b_{t}=(1+\theta) \frac{\frac{t}{\sigma_{\epsilon}^{2}}}{\frac{t}{\sigma_{\epsilon}^{2}}+\zeta_{t}} \\
& c_{t}=\gamma\left(\frac{t}{\sigma_{\epsilon}^{2}}+\zeta_{t}\right)^{-1}
\end{aligned}
$$

In particular, note $\frac{b_{t}}{c_{t}}=\frac{1+\theta}{\gamma} \cdot \frac{t}{\sigma_{\epsilon}^{2}}$, and plugging this into our expression for $\zeta_{t}$, one obtains:

$$
\zeta_{t}=\frac{1}{\sigma_{V}^{2}}+\frac{(1+\theta)^{2}}{\gamma^{2} \sigma_{S}^{2}} \sum_{r=1}^{t-1} \frac{r^{2}}{\sigma_{\epsilon}^{4}}=\frac{1}{\sigma_{V}^{2}}+\frac{(1+\theta)^{2}}{\gamma^{2} \sigma_{S}^{2} \sigma_{\epsilon}^{4}} \frac{(t-1) t(2 t-1)}{6}
$$

Consider now the average price $\overline{p_{t}}$, obtained under the average shock $S_{t}=0$. Plugging in $E_{t}^{p}$ and then $\zeta_{t}$ we find:

$$
\overline{p_{t}}=(1+\theta)\left(\frac{\frac{t}{\sigma_{\epsilon}^{2}}+\zeta_{t}-\frac{1}{\sigma_{V}^{2}}}{\frac{t}{\sigma_{\epsilon}^{2}}+\zeta_{t}}\right) V=\frac{(1+\theta)\left(\frac{t}{\sigma_{\epsilon}^{2}}+\frac{(1+\theta)^{2}}{\gamma^{2} \sigma_{S}^{2} \sigma_{\epsilon}^{4}} \frac{(t-1) t(2 t-1)}{6}\right)}{\left(\frac{1}{\sigma_{V}^{2}}+\frac{t}{\sigma_{\epsilon}^{2}}+\frac{(1+\theta)^{2}}{\gamma^{2} \sigma_{S}^{2} \sigma_{\epsilon}^{4}} \frac{(t-1) t(2 t-1)}{6}\right)} V
$$

Proposition 3. Under learning from prices, the price at time $\mathrm{t}$ is $p_{t}=\mathbb{E}_{t}^{\theta}\left(V \mid p_{t-1}, \ldots, p_{1} ; \vec{s}_{t}, \ldots, \vec{s}_{1}\right)$. From Proposition 2, the average price path is:

$$
p_{t}=(1+\theta)\left[\frac{\frac{t}{\sigma_{\epsilon}^{2}}+\left(\frac{1+\theta}{\sigma_{S} \sigma_{\epsilon}^{2}}\right)^{2} \frac{t(t-1)(2 t-1)}{6}}{\frac{t}{\sigma_{\epsilon}^{2}}+\frac{1}{\sigma_{\mathrm{V}}^{2}}+\left(\frac{1+\theta}{\sigma_{S} \sigma_{\epsilon}^{2}}\right)^{2} \frac{t(t-1)(2 t-1)}{6}}\right] V
$$

To explore convexity, rewrite price as:

$$
p_{t}=(1+\theta) V \frac{f}{f+c}
$$


where $f=k_{1} t+k_{2} t(t-1)(2 t-1), c=\frac{1}{\sigma_{\mathrm{V}}^{2}}, k_{1}=\frac{t}{\sigma_{\epsilon}^{2}}$ and $k_{2}=\frac{1}{6}\left(\frac{1+\theta}{\sigma_{S} \sigma_{\epsilon}^{2}}\right)^{2}$. Note that, up to a constant, we have:

$$
\partial_{t}^{2} p_{t}=\partial_{t} \frac{f^{\prime}}{(f+c)^{2}}=(f+c)^{-2}\left[f^{\prime \prime}-\frac{2\left(f^{\prime}\right)^{2}}{(f+c)}\right]
$$

which has the same sign as $f^{\prime \prime}-\frac{2(f \prime)^{2}}{(f+c)}$. This is positive when:

$$
c>\frac{2\left(f^{\prime}\right)^{2}}{f^{\prime \prime}}-f
$$

Convexity requires $c$ to be large, that is $\sigma_{\mathrm{V}}^{2}$ to be small. For example, convexity at $t=1$ requires:

$$
c>\frac{k_{1}^{2}-k_{1} k_{2}+k_{2}^{2}}{3 k_{2}}
$$

Rewrite the condition above as:

$$
f^{\prime \prime} c>2\left(f^{\prime}\right)^{2}-f f^{\prime \prime}
$$

that is

$$
6 k_{2}(2 t-1) c>2\left(k_{1}+k_{2}\left(6 t^{2}-6 t+1\right)\right)^{2}-6 k_{2}(2 t-1)\left(k_{1} t+k_{2}\left(2 t^{3}-3 t^{2}+t\right)\right)
$$

As we are looking near $t=1$, let us set $s=t-1$. Then, the inequality simplifies to:

$$
6 k_{2}(2 s+1) c>48 k_{2}^{2} s^{4}+96 k_{2}^{2} s^{3}+66 k_{2} s^{2}+12 k_{1} k_{2} s^{2}+18 k_{2}^{2} s+6 k_{1} k_{2} s+2 k_{1}^{2}+2 k_{2}^{2}-2 k_{1} k_{2}
$$

In particular, the right-hand side is a quartic with positive coefficients (and in particular it is convex in $s$ ), whereas the left hand side is a linear function. Hence, if the left-hand side lies above the right hand side at $t=1$, the two will cross at $t=t^{*}>1$, and never cross again. Hence, for the average price path to be convex at $t \in\left[1, t^{*}\right]$ and concave afterwards, it is necessary and sufficient for the above inequality to hold at $s=0$, which is given by:

$$
c>\frac{k_{1}^{2}-k_{1} k_{2}+k_{2}^{2}}{3 k_{2}} \rightarrow \sigma_{V}^{2}<\left(\frac{k_{1}^{2}-k_{1} k_{2}+k_{2}^{2}}{3 k_{2}}\right)^{-1}=\sigma_{V}^{* 2}
$$

as desired.

Proposition 4. Consider the price path

$$
p_{t}=(1+\theta)^{T-t+1}\left[\prod_{r=t}^{T} \pi_{r}\right] V
$$


where $\pi_{t}=\frac{t}{t+\frac{\sigma_{\epsilon}^{2}}{\sigma_{\mathrm{V}}^{2}}}$ and denote $\hat{\pi} \equiv\left[\prod_{r=1}^{T} \pi_{r}\right]^{\frac{1}{T}}$. First note that $p_{t}-p_{t-1}=p_{t}\left[1-(1+\theta) \pi_{t-1}\right]$. So price increases at $t$ if $(1+\theta) \pi_{t-1}<1$ and it decreases otherwise. Because $\pi_{t}$ is monotonic, it follows that the price path is either always increasing (if $(1+\theta) \pi_{T}<1$ ), or always decreasing (if $(1+\theta) \pi_{1}>1$ ) or is first increasing and then decreasing. This holds provided $(1+\theta) \pi_{1}<1<(1+\theta) \pi_{T}$, which reads $\theta \in$ $\left(\frac{\sigma_{\epsilon}^{2}}{T \sigma_{V}^{2}}, \frac{1-\hat{\pi}}{\hat{\pi}}\right)$. In particular, we then have both $p_{1}=(1+\theta)^{T}\left[\prod_{r=1}^{T} \pi_{r}\right] V<V$ and $p_{T}=(1+\theta) \pi_{T} V>V$.

Proposition 5. For simplicity, set $a_{2, t}=a_{t}$. As indicated in the paper, we obtain:

$$
\begin{gathered}
\mathbb{E}_{i, t}^{\theta}\left(p_{t+1}\right)=(1+\theta)\left[a_{t+1} \mathbb{E}_{i, t}\left[\mathbb{E}\left(V \mid P_{t+1}\right)\right]+b_{t+1} \mathbb{E}_{i, t}(V)\right] \\
\operatorname{Var}_{t}\left(p_{t+1}\right)=\left[a_{t+1}\left(1-\frac{\zeta_{t}}{\zeta_{t+1}}\right)+b_{t+1}\right]^{2} \operatorname{Var}_{t}\left(s_{t+1}^{p}\right) .
\end{gathered}
$$

where $\zeta_{t}=\frac{1}{\sigma_{p, t}^{2}}$. Integrating across $i$, we obtain:

$$
\begin{aligned}
& p_{t}=\overline{\mathbb{E}}_{t}^{\theta}\left[p_{t+1}\right]-\gamma \operatorname{Var}_{t}\left[p_{t+1}\right] S_{t} \quad \text { for } t<T \\
& p_{T}=\overline{\mathbb{E}}_{t}^{\theta}[V]-\gamma \sigma_{T}^{2}(V) S_{T} \\
& \overline{\mathbb{E}}_{t}^{\theta}\left(p_{t+1}\right)=(1+\theta)\left[a_{t+1} \overline{\mathbb{E}}_{t}\left[\mathbb{E}\left(V \mid P_{t+1}\right)\right]+b_{t+1} \overline{\mathbb{E}}_{t}(V)\right] \\
& \operatorname{Var}_{t}\left(p_{t+1}\right)=\left[a_{t+1}\left(1-\frac{\zeta_{t}}{\zeta_{t+1}}\right)+b_{t+1}\right]^{2} \operatorname{Var}_{t}\left(s_{t+1}^{p}\right) .
\end{aligned}
$$

Hence, to pin down the equilibrium coefficients, one needs to evaluate $\overline{\mathbb{E}}_{t}\left[\mathbb{E}\left(V \mid P_{t+1}\right)\right]$ and $\operatorname{Var}_{t}\left(s_{t+1}^{p}\right)$. We calculate the quantities in the following lemma.

Lemma 2. Denote $\zeta_{t}=\frac{1}{\sigma_{p, t}^{2}}$ and let $E_{t}^{p}=E\left[V \mid P_{t}\right]$ denote the expectation of the fundamentals only using prices. The average rational expectation of the future public expectation of the fundamentals is given by:

$$
\overline{\mathbb{E}}_{t}\left[\mathbb{E}\left(V \mid P_{t+1}\right)\right]=\frac{\zeta_{t}}{\zeta_{t+1}} E_{t}^{p}+\left(1-\frac{\zeta_{t}}{\zeta_{t+1}}\right) \overline{\mathbb{E}}_{t}[V]
$$

The conditional variance of the future price signal is given by:

$$
\operatorname{Var}_{t}\left(s_{t+1}^{p}\right)=\frac{1}{\zeta_{t}+\frac{t}{\sigma_{\epsilon}^{2}}}+\frac{c_{t+1}^{2}}{b_{t+1}^{2}} \sigma_{S}^{2}
$$

\section{Proof.}




$$
\begin{aligned}
\overline{\mathbb{E}}_{t}\left[E_{t+1}^{p}\right] & =\overline{\mathbb{E}}_{t}\left[\frac{1}{\zeta_{t+1}} \frac{1}{\sigma_{S}^{2}}\left(\sum_{r=1}^{t+1} \frac{b_{r}^{2}}{c_{r}^{2}}\left(V-\frac{c_{r}}{b_{r}} S_{r}\right)\right)\right] \\
& =\frac{\zeta_{t}}{\zeta_{t+1}} E_{t}^{p}+\overline{\mathbb{E}}_{t}\left[\frac{1}{\zeta_{t+1}} \frac{1}{\sigma_{S}^{2}}\left(\frac{b_{t+1}^{2}}{c_{t+1}^{2}}\left(V-\frac{c_{t+1}}{b_{t+1}} S_{t+1}\right)\right)\right] \\
& =\frac{\zeta_{t}}{\zeta_{t+1}} E_{t}^{p}+\overline{\mathbb{E}}_{t}\left[\frac{1}{\zeta_{t+1}}\left(\zeta_{t+1}-\zeta_{t}\right) V\right]
\end{aligned}
$$

which gives the first result. Second, note that as $s_{t+1}^{p}=V-\frac{c_{t+1}}{b_{t+1}} S_{t+1}$, the conditional variance of the term should be the addition of two separate variances

$$
\sigma_{t}^{2}(V)+\left(\frac{c_{t+1}}{b_{t+1}}\right)^{2} \sigma_{S}^{2}=\frac{1}{\zeta_{t}+\frac{t}{\sigma_{\epsilon}^{2}}}+\frac{c_{t+1}^{2}}{b_{t+1}^{2}} \sigma_{S}^{2}
$$

as desired.

Plugging the results of the lemma, we obtain:

$$
\begin{gathered}
\overline{\mathbb{E}}_{t}^{\theta}\left(p_{t+1}\right)=\left[(1+\theta) a_{t+1} \frac{\zeta_{t}}{\zeta_{t+1}}\right] E_{t}^{p}+\left[(1+\theta) a_{t+1}\left(1-\frac{\zeta_{t}}{\zeta_{t+1}}\right)+b_{t+1}\right] \overline{\mathbb{E}}_{t}(V) \\
\operatorname{Var}_{t}\left(p_{t+1}\right)=\left[a_{t+1}\left(1-\frac{\zeta_{t}}{\zeta_{t+1}}\right)+b_{t+1}\right]^{2}\left[\frac{1}{\zeta_{t}+\frac{t}{\sigma_{\epsilon}^{2}}}+\frac{c_{t+1}^{2}}{b_{t+1}^{2}} \sigma_{S}^{2}\right] . \\
p_{t}=\left[(1+\theta) a_{t+1} \frac{\zeta_{t}}{\zeta_{t+1}}\right] E_{t}^{p}+\left[(1+\theta) a_{t+1}\left(1-\frac{\zeta_{t}}{\zeta_{t+1}}\right)+b_{t+1}\right] \overline{\mathbb{E}}_{t}(V) \\
-\gamma\left[a_{t+1}\left(1-\frac{\zeta_{t}}{\zeta_{t+1}}\right)+b_{t+1}\right]\left[\frac{1}{\zeta_{t}+\frac{t}{\sigma_{\epsilon}^{2}}}+\frac{c_{t+1}^{2}}{b_{t+1}^{2}} \sigma_{S}^{2}\right] S_{t} \quad \text { for } t<T \\
p_{T}=(1+\theta) \overline{\mathbb{E}}_{t}[V]-\gamma \sigma_{T}^{2}(V)
\end{gathered}
$$

To conclude, recall that $\overline{\mathbb{E}}_{t}[V]=\frac{\frac{t}{\sigma_{\epsilon}^{2}}}{\frac{t}{\sigma_{\epsilon}^{2}}+\zeta_{t}} V+\frac{\zeta_{t}}{\frac{t}{\sigma_{\epsilon}^{2}}+\zeta_{t}} E_{t}^{p}$. Matching coefficients to the price rule: $p_{t}=$ $a_{t} \mathbb{E}\left(V \mid P_{t}\right)+b_{t} V-c_{t} S_{t}$, we obtain the results. In particular, one can easily see that $a_{t}+b_{t}=$ $(1+\theta)\left(a_{t+1}+b_{t+1}\right)$ and $a_{T}+b_{T}=1+\theta$, which gives us $a_{t}+b_{t}=(1+\theta)^{T-t+1}$, as desired.

Proposition 6. From the update equations in Proposition 5, note that: 


$$
\zeta_{T-1}=\zeta_{T}-\frac{1}{\sigma_{S}^{2}} \frac{(1+\theta)^{2} T^{2}}{\gamma^{2} \sigma_{\epsilon}^{4}}
$$

And in general, one can obtain from the above update equations:

$$
\begin{aligned}
& \zeta_{t-1}=\zeta_{t}-\frac{1}{\sigma_{S}^{2}}\left(\frac{t}{\sigma_{\epsilon}^{2} \gamma} \cdot \frac{1}{(1+\theta)^{T+1-t}\left(1+\frac{t}{\zeta_{t+1} \sigma_{\epsilon}^{2}}\right)+\frac{\zeta_{t}+\frac{t \zeta_{t}}{\sigma_{\epsilon}^{2} \zeta_{t+1}}}{\zeta_{t+1}-\zeta_{t}} b_{t+1}}\right)^{2} \\
& b_{t}=\frac{\frac{t}{\sigma_{\epsilon}^{2}}}{\frac{t}{\sigma_{\epsilon}^{2}}+\zeta_{t}}\left(\left(1-\frac{\zeta_{t}}{\zeta_{t+1}}\right)(1+\theta)^{T+1-t}+\frac{\zeta_{t}}{\zeta_{t+1}} b_{t+1}\right)
\end{aligned}
$$

Hence, one immediate obtains that $b_{t} \geq 0$. Plugging the inequality above, one obtains:

$$
\zeta_{t-1} \geq \zeta_{t}-\frac{1}{\sigma_{S}^{2}} \frac{t^{2}}{\sigma_{\epsilon}^{4}} \frac{1}{(1+\theta)^{2(T+1-t)}}
$$

Hence, we have a linear lower bound on $\zeta_{t-1}$ in terms of the preceding $\zeta_{t}$. The series of lower bound, together with the first update equation, implies that $\zeta_{0}$ can grow arbitrarily large as $\zeta_{T}$ increases.

On the other hand, by the first update equation one can send $\zeta_{T-1}$ arbitrarily close to 0 , as $\zeta_{T} \mapsto$ $\frac{1}{\sigma_{S}^{2}} \frac{(1+\theta)^{2} T^{2}}{\gamma^{2} \sigma_{\epsilon}^{4}}$. Hence, as $\zeta_{t-1} \leq \zeta_{t}$ for all $t$, by induction one can show that $\zeta_{t}$ can go arbitrarily close to 0 as $\zeta_{T}$ decreases. Consequently, as all of the transition functions are continuous, we can conclude via the intermediate value theorem that there exists an equilibrium such that $\zeta_{0}=\frac{1}{\sigma_{V}^{2}}$. 